\title{
Long noncoding RNA DPP10-AS1 promotes malignant processes through epigenetically activating its cognate gene DPP10 to predict poor prognosis in lung cancer patients
}

\author{
Haihua Tian \\ Medical School of Ningbo University \\ Jinchang Pan \\ Medical School of Ningbo University \\ Shuai Fang \\ Medical School of Ningbo University
}

Chengwei Zhou

Medical School of Ningbo University

Hui Tian

The Affiliated Lihuili Hospital of Medical School of Ningbo University

Jinxian He

The Affiliated Lihuili Hospital of Medical School of Ningbo University

\section{Weiyu Shen}

The Affiliated Lihuili Hospital of Medical School of Ningbo University

\section{Xiaodan Meng}

Medical School of Ningbo University

\section{Xiaofeng Jin}

Medical School of Ningbo University

\section{Zhaohui Gong ( $\nabla$ zhaohui@ncri.org.cn )}

Medical School of Ningbo University https://orcid.org/0000-0002-5662-2752

\section{Research article}

Keywords: antisense long noncoding RNA; DPP10-AS1; hypomethylation; malignant process; DPP10

Posted Date: March 4th, 2020

DOI: https://doi.org/10.21203/rs.2.16166/v2

License: (c) (1) This work is licensed under a Creative Commons Attribution 4.0 International License. Read Full License 
Page $2 / 30$ 


\section{Abstract}

Background: Long noncoding RNAs (IncRNAs) play oncogenic or tumor-suppressive roles in various cancers. However, the epigenetic modification of IncRNA and its cognate sense gene in lung cancer remain largely unknown.

Methods: qRT-PCR and Western blot were conducted to detect the expressions of DDP10-AS1 and DPP10 expression in lung cancer cell lines and tissues. The impact of DDP10-AS1 on DPP10 expression, cell growth, invasion, apoptosis and in vivo tumor growth were investigated in lung cancer cells by Western blot, rescue experiments, colony formation, flow cytometry and xenograft animal experiment.

Results: A novel antisense IncRNA, DPP10-AS1, is found to be highly expressed in cancer tissues and the upregulation of DPP10-AS1 predicts poor prognosis in lung cancer patients. Notably, DPP10-AS1 promotes lung cancer cell growth, colony formation, cell cycle progression and represses apoptosis in lung cancer cells by upregulating DPP10 expression. Additionally, DPP10-AS1 facilitates lung tumor growth via upregulation of DPP10 protein in xenograft mouse model. Importantly, DPP10-AS1 positively regulates $D P P 10$ gene expression and they are coordinately upregulated in lung cancer tissues. Mechanically, DPP10-AS1 associates with DPP10 mRNA but does not enhance DPP10 mRNA stability. Hypomethylation of DPP10-AS1 and DPP10 contributes to their coordinate upregulation in lung cancer.

Conclusions: These findings indicate that the upregulated antisense IncRNA DPP10-AS1 promotes lung cancer malignant processes and facilitates tumorigenesis by epigenetically regulating its cognate sense gene DPP10, and DPP10-AS1 may act as a candidate prognostic biomarker and a potential therapeutic target in lung cancer.

\section{Background}

Long noncoding RNAs $\$ IncRNAs $\llbracket$ are a class of non-coding RNAs comprised of $>200$ nucleotides with limited protein-coding ability [1, 2]. These IncRNAs were once regarded as transcriptional noise[3], subsequent studies have demonstrated that IncRNAs participate in various biological processes, including epigenetic control, the regulation of gene expression, RNA maturation (including splicing and editing) and the maintenance of chromatin structure[4-6]. LncRNAs can act as key regulators in the development and progression of cancers through pathophysiological activities such as cell growth, apoptosis, invasion, and metastasis[7, 8]. Previous studies have proved that IncRNAs such as HOTAIR (Hox transcript antisense intergenic RNA) and MALAT1 (metastasis-associated lung adenocarcinoma transcript 1) are upregulated in lung cancer and are associated with enhanced proliferation, metastasis and predict poor prognosis[9, 10]. Another IncRNA, MIR22HG, could stabilize the YBX1 protein and predict poor survival in lung cancer patients[11]. The antisense IncRNAs are a subtype of IncRNA molecules transcribed from the opposite DNA strand of protein-coding and non-protein-coding gene compared with sense transcripts and overlap in part with sense RNAs[12]. Recently, it has been found that the antisense 
IncRNA, AGAP2-AS1, acts as an oncogene to promote lung cancer cell proliferation, invasion, migration and inhibit apoptosis by repressing the transcriptions of tumor-suppressor LATS2 and KLF2[13]. However, the role of antisense IncRNA in lung cancer diagnosis and malignant process, and the mechanism of interaction between antisense IncRNA and its associated gene in lung cancer remain largely unknown.

In our previous work, we identified the differentially expressed IncRNAs in lung cancer patients by IncRNA array and found the circulating IncRNA XLOC_009167 as a diagnostic biomarker to predict lung cancer[14]. Among the differentially expressed IncRNAs, DPP10-AS1 is an intergenic antisense IncRNA with a 744-nt in length and locates on chromosome 2q14.1. However, the biological function of DPP10AS1 in lung cancer is unknown. In this study, we found that the upregulated DPP10-AS1 was significantly correlated with the higher serum CYFRA21-1, larger tumor size, advanced TNM stage and predicted poor prognosis in lung cancer patients. Further assays revealed that DPP10-AS1 promoted cell proliferation, cell cycle progression and inhibited apoptosis by regulating its target gene DPP10. The results suggest that DPP10-AS1 may serve as an oncogenic IncRNA that participates in lung cancer development and aggressive progression. In addition, DPP10-AS1 has the potential to become a new biomarker for lung cancer diagnosis and therapy.

\section{Methods}

\section{Patients and tissue preparation.}

During the period from January 2014 to December 2017, lung primary cancer tissue specimens and cancer-adjacent tissues were collected from the patients underwent the radical surgery of lung cancer or palliative resection of lung cancer at the Affiliated Hospital of Medical School of Ningbo University and Ningbo Medical Center Lihuili Eastern Hospital. The cancer-adjacent tissues must be at least 5 centimeters apart from the edge of the cancer tissues. We have collected 94 specimens, where patients were all diagnosed as primary lung cancer, and were not treated by preoperative radiotherapy, chemotherapy, targeted therapy, and immunotherapy. Meanwhile, the general clinical information and detailed pathological records were collected. Written informed consent was obtained from all patients and the study protocol was approved by the Clinical Research Ethics Committee of Medical School of Ningbo University. The overall survivals of these patients were followed up with a median period of 20 months. Overall survival (OS) was calculated from the date of surgery to the date of mortality or the last follow-up. Recurrence-free survival (RFS) was calculated from the date of surgery to the date of first recurrence or the last follow-up.

\section{Cell cultures and transient transfection.}

The normal human bronchial epithelial cell BEAS-2B and the human lung cancer cell lines A549, H446, SPC-A1 and NCl-H1299 were obtained from a cell bank at the Chinese Academy of Sciences (Shanghai, China). All human lung cancer cell lines were cultured in RPMI-1640 (HyClone, USA), with $10 \%$ fetal bovine serum (PAN, Germany). They were maintained in a humidified chamber/incubator containing $5 \%$ 
$\mathrm{CO}_{2}$ at $37^{\circ} \mathrm{C}$. BEAS-2B was maintained in Dulbecco's modified Eagle's medium (DMEM) that was supplemented with $10 \%$ FBS. All oligonucleotides and plasmids were transfected into SPC-A1 and NClH1299 cells using the Lipofectamine 2000 Transfection Reagent (Invitrogen, USA) according to the manufacturer's protocol. The transfected cells were harvested at 24 or $48 \mathrm{~h}$ after transfection. The sequences of the siRNA oligonucleotides were synthesized by GenePharma (Shanghai, China) and shown in Additional File 1, Table S1.

\section{RNA Extraction and quantitative reverse transcription polymerase chain reaction (qRT-PCR).}

Total RNA was extracted by Trizol reagent (Invitrogen, USA), followed by cDNA synthesis using PrimeScript $^{\text {TM }}$ II 1st strand cDNA Synthesis Kit (TaKaRa, Japan) following the standard protocol. qRT-PCR was subsequently carried out with SYBR Premix $\operatorname{Ex~Taq~}^{\text {TM }}$ II (TaKaRa, Japan) according to manufacturer's instructions, and was run on a PCR device Mx3005P (Stratagene, USA) and were normalized to levels of $\beta$-actin mRNA. The comparative $2^{-\Delta \mathrm{Ct}}$ method was used for relative quantification and statistical analysis. To account for the assessment of technical variability, the assays was performed in triplicate for each case. Primer sequences are shown in Additional File 1, Table S2.

\section{Recombinant plasmid construction.}

The sequences of DPP10-AS1 and DPP10 were amplified by PCR from the genomic DNA of SPC-A1 or $\mathrm{NCl}-\mathrm{H} 1299$ cell lines, and were cloned into linearized pcDNA 3.1 plasmid (Biogle, China) as described in our previous work[15]. Primer sequences are shown in Additional File 1, Table S2.

\section{Protein isolation and Western blot.}

Cells were firstly lysed in RIPA protein extraction regent (Beyotime, China) plus $1 \mathrm{mM}$ phosphatase inhibitor PMSF (Beyotime, China). Protein concentration was measured with BCA protein assay kit

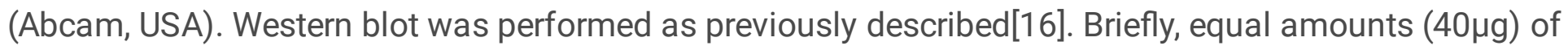
protein were separated by $8 \%$ SDS-PAGE, and then transferred onto polyvinylidene fluoride membrane (Millipore, USA). Subsequently, the membrane was blocked with TBS/0.1\% Tween-20, supplemented with $5 \%$ skimmed milk for $1 \mathrm{~h}$ at room temperature and then incubated with primary antibodies against DPP10 (1:3000), $\beta$-actin (1:5000) at $4^{\circ} \mathrm{C}$ overnight, washed with TBS containing $0.1 \%$ Tween-20 and then incubated with secondary antibodies. The primary antibodies were: anti- $\beta$-actin antibody (sc-25778, Santa Cruz, USA), anti-DPP10 antibody (ab-111985, Abcam, USA). Finally, the membranes were incubated with secondary antibody, rabbit anti-goat IgG-HRP BA-1060 (Boster, China) and goat anti-mouse IgG BA1050 (Boster, China), and visualized with the infrared imaging system (Li-COR, USA). The immunoreactive bands were quantified by the densitometry with ImageJ software when necessary.

\section{Nuclear and cytoplasmic RNA fractionation analysis.}

Nuclear and cytosolic fractions were separated using the PARIS kit (Am1921, Thermo Fisher Scientific, USA) according to the manufacturer's instructions. Then, the expression levels of $\beta$-actin, U6 and DPP10- 
AS1 in nuclear and cytoplasm SPC-A1 cells were detected using qRT-PCR assays.

\section{RNase protection assay.}

pcDNA3.1-DPP10-AS1, pcDNA3.1, siNC and siDPP10-AS1 were cotransfected into SPC-A1 and NCI-H1299 cells. Forty-eight hours later, the RNA was extracted from the cells, and then treated with RNase A+T (Thermo Fisher Scientific, USA) for 1 hour at $37^{\circ} \mathrm{C}$. Single-stranded RNA was digested with RNase A+T, and remaining double-stranded RNA was extracted and analyzed by real-time qPCR.

\section{MTT assay.}

Briefly, SPC-A1 and NCl-H1299 cells were seeded into 96-well plates at an initial concentration of 5囚103 cells/well in 1640 supplemented with 10\% FBS .Cells were allowed to grow for 24, 48, 72 and $96 \mathrm{~h}$. And then $20 \mu \mathrm{l}$ of $5 \mathrm{mg} / \mathrm{ml} \mathrm{MTT}$ (Sigma-Aldrich, USA) was added into each well and cultured at $37^{\circ} \mathrm{C}$ for $4 \mathrm{~h}$. Following the incubation, cells were lysed with $150 \mu$ LMSO. Formazan crystals were dissolved in dimethyl sulfoxide. A microplate reader (Labsystems, Finland) was used to measure the OD values at a wavelength of $490 \mathrm{~nm}$. Each experimental group contained three replicate wells, and the experiment was repeated three times.

\section{Colony formation assay.}

After transfection with siRNAs or constructed plasmids, cells were collected and resuspended in cell culture medium. Five hundred cells were seeded into 6-well plate and cultured at $37^{\circ} \mathrm{C}$ with $5 \% \mathrm{CO}_{2}$. Following incubation for 13 days, cell colonies were washed with $1 \times P B S$ for 3 times. The colonies were fixed with pre-iced methanol and stained with $0.1 \%$ crystal violet at room temperature for $10 \mathrm{~min}$.

\section{Cell cycle analysis.}

Cells were cultured in 6-well plates overnight and then transfected with siRNAs or constructed plasmids using Lipofectamine 2000 after hunger treatment for 24 hours. After 24-h transfection, cells were collected and washed with cold 1×PBS. Next, cells were rewashed with cold 1×PBS and incubated with $\mathrm{PI} / \mathrm{RN}$ ase staining buffer (Multisciences, USA). Cells were analyzed with a FACS calibur flow cytometer $(\mathrm{BD}, \mathrm{USA})$.

\section{Cell apoptosis assay.}

Cell apoptosis was measured using Annexin V-FITC/PI Apoptosis Detection Kit (Multisciences, USA). In brief, cells were seeded in 6-well plates one day before transfection. After $24 \mathrm{~h}$, cells were collected and washed with cold $1 \times$ PBS. Before analysis, cells were resuspended with $500 \mu \mathrm{l}$ binding buffer plus $5 \mu \mathrm{II}$ and $5 \mu \mathrm{l}$ FITC-conjugated anti-Annexin $\mathrm{V}$ antibody. After the incubation in the dark for $15 \mathrm{~min}$ at room temperature, cells were analyzed by FACS calibur flow cytometer (BD, USA) equipped with Cell Quest software (BD Biosciences). 


\section{In vivo tumorigenesis assay.}

The experiments were performed in accordance with the approved guidelines by the Laboratory Animal Ethical Committee at Ningbo University. Four-week-old male nude mice were purchased at Shanghai SLAC Laboratory Animals Co., Ltd (Shanghai, China). We screened lung cancer cells that can stable

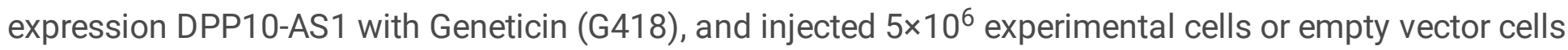
into mice by subcutaneous tumor formation ( 8 mice for each group) The tumor dimensions were measured every two days, and after 4 weeks, the mice were sacrificed by cervical dislocation and the tumor were excised for weighing. The tumor volume was calculated with the formula: (length $\times$ width $\left.^{2}\right) / 2$.

\section{Statistical analysis.}

The statistical analyses were performed by using GraphPad 7.0 (GraphPad, USA). Data were presented as mean $\pm S D$ from at least three separate experiments. The differences between DPP10-AS1 or DPP10 expression levels in lung cancer tissues and pair-matched noncancerous tissues were compared using the Wilcoxon signed-rank test. The Chi-squared test ( $\chi 2$ test) was used to evaluate the relationship between the clinicopathological features and DPP10-AS1 expression. Two sample comparisons were applied with Student's t-test for equal or unequal variance or Pearson correlation test. Mann-Whitney U test was used to assess the differential expression levels of DPP10-AS1 and DPP10 in patient cohorts. The relationship between DPP10-AS1 and DPP10 expression was analyzed by Pearson's correlation. For patients with different levels of DPP10-AS1 expression, the survival curves were plotted using the KaplanMeier method and compared using the log-rank test. The multivariate survival analysis was performed on all parameters that were found to be significant in univariate analysis using the Cox regression model. For all analyses, a $P$-value $<0.05$ was considered statistically significant. All $P$-values are two sided.

\section{Results}

\section{DPP10-AS1 is upregulated in lung cancer and predicts poor prognosis in patients.}

To confirm the expression of DPP10-AS1 in lung cancer tissues, we performed qRT-PCR to detect DPP10AS1 in 94 pairs of lung cancer tissues and adjacent noncancerous tissues. The result showed that the expression of DPP10-AS1 in tumor tissues of lung cancer patients was significantly higher than that in corresponding normal tissues $(P<0.0001$, Figure 1A). More specifically, $72 \%(68 / 94)$ of lung cancer patients showed an increase of DPP10-AS1 in tumor tissues compared to adjacent noncancerous tissues (Figure 1B). To further investigate the association between the DPP10-AS1 expression and the clinicopathological characteristics, 94 lung cancer samples were divided into two subgroups according to the relative DPP10-AS1 expression with median ratio: high DPP10-AS1 group ( $n=47$, DPP10-AS1 ratio $\geq$ median ratio) and low DPP10-AS1 group ( $\mathrm{n}=47$, DPP10-AS1 ratio < median ratio). Correlation regression analysis showed that high DPP10-AS1 expression in lung cancer patients was closely related to serum high CYFRA21-1 level $(P=0.014)$, large tumor size $(P=0.0079)$, and advanced TNM stage $(P=0.0406)$. However, age $(P=0.3279)$, gender $(P=0.0988)$, tumor number $(P=0.1438)$, microvascular invasion 
$(P=0.4532)$, and smoking history ( $P=0.2049)$ were not correlated with DPP10-AS1 expression (Table 1$)$. To further evaluate the prognostic value of DPP10-AS1 in lung cancer patients, we analyzed the association between DPP10-AS1 expression and survival duration using Kaplan-Meier analysis with the log-rank test. The results revealed that lung cancer patients with higher DPP10-AS1 expression had a significantly poor recurrence-free survival (RFS) compared to those with lower DPP10-AS1 expression (log rank=9.329, $P=0.0025$, Figure $1 C$ ). Similarly, the lung cancer patients with higher DPP10-AS1 expression predicted a poorer overall survival (OS) compared to those with lower DPP10-AS1 expression (log rank=9.333, $P=0.036$, Figure 1D). Cox proportional hazards regression analysis further showed that high DPP10-AS1 expression in lung cancer tissues was an independent predictor for worse RFS (Table 2) and OS (Table 3). These results indicated that DPP10-AS1 expression is upregulated in lung cancer tissues and predicts poor prognosis in lung cancer patients.

We also measured the DPP10-AS1 expression levels in 5 lung cancer cell lines and human normal bronchial epithelial cells (BEAS-2B) by qRT-PCR. As shown in Figure 1E, the relative DPP10-AS1 expression in lung cancer cells (A549, SPC-A1 and NCl-H1299) were significantly upregulated (5 57-fold change) compared to that in human normal bronchial epithelial cells. Thus, SPC-A1 and NCl-H1299 cell lines were selected for the subsequent assays. Collectively, these results indicate that DPP10-AS1 is elevated in vivo and in vitro, and is considered as an independent prognostic factor of outcomes in patients with lung cancer.

\section{DPP10-AS1 promotes lung cancer cell proliferation in vitro and facilitates tumor growth in xenograft animal model.}

Since the results indicated that the significant upregulation of DPP10-AS1 in lung cancer specimens was associated with larger tumor size, the effect of DPP10-AS1 on lung cancer cell growth needs to be explored. To regulate DPP10-AS1 expression in lung cancer cells, the endogenous expression of DPP10AS1 was inhibited by transfection of siRNA and overexpressed by transfection of pcDNA3.1-DPP10-AS1, respectively. The results showed that DPP10-AS1 was downregulated up to 50 60\% by siRNA knockdown (Additional File 2, Figure S1A), and was upregulated up to 250 300 fold by overexpression (Additional File 2, Figure S1B). The MTT assays indicated that knockdown of endogenous DPP10-AS1 expression dramatically inhibited the growth of SPC-A1 and NCl-H1299 cells (Figure 2A, B). In contrast, overexpression of DPP10-AS1 significantly promoted cell growth in both cell lines (Figure 2C, D). Further colony formation assays showed that downregulation of DPP10-AS1 could significantly inhibit the colony formation in both SPC-A1 and NCl-H1299 cells (Figure 2E, F). In contrast, overexpression of DPP10-AS1 promoted the colony formation in these two cell lines (Figure $\mathbf{2 G}, \mathbf{H}$ ). To further confirm the effect of DPP10-AS1 on the lung tumor growth in vivo, two lung cancer cell lines (SPC-A1 and NCl-H1299) stably expressing DPP10-AS1 were screened by geneticin (G418) and were injected subcutaneously into nude mice to establish xenograft tumor model (Figure 2I). The results showed that overexpression of DPP10-AS1 promoted the tumor growth in the volume (Figure 2J) and tumor weight (Figure 2K) via injection of SPC-A1 cells in the xenograft animal model. Similar effect was found in the NCI-H1299 cellderived xenograft animal model (Figure $2 \mathrm{~L}, \mathbf{M}$ ). In addition, compared with the negative control 
(pcDNA3.1), pcDNA3.1-DPP10-AS1 resulted in the increase of IncRNA DPP10-AS1 (Figure 2N) and DPP10 mRNA (Figure 20) in SPC-A1 cell-derived tumor tissues. Similarly, the same results were obtained in NClH1299 cell-derived tumor tissues (Figure 2P, Q). At the protein level, overexpression of IncRNA DPP10-AS1 promoted its cognate DPP10 protein expression (Figure 2R). Thus, the data suggest that DPP10-AS1 promotes lung cancer cell growth and colony formation in vitro, and facilitates lung tumor growth via upregulation of DPP10 protein in xenograft animal model.

\section{DPP10-AS1 promotes cell cycle progression and represses apoptosis of lung cancer cells.}

To probe the potential mechanisms by which DPP10-AS1 enhanced lung cancer cell proliferation, we assessed cell cycle and apoptosis in SPC-A1 and NCI-H1299 cells after the treatment of DPP10-AS1 knockdown or overexpression. Flow cytometric cell cycle assays demonstrated that knockdown of DPP10-AS1 led to a significant accumulation at G0/G1 phase and a significant decrease at G2/M-phase in both two cell lines (Figure 3A). Conversely, overexpression of DPP10-AS1 mainly resulted in a remarkable reduction in the G0/G1 population and an increase at G2/M phase in the two cell lines (Figure 3B). Moreover, the cell apoptosis assays indicated that knockdown of DPP10-AS1 significantly increased the early and late apoptosis in both SPC-A1 and NCI-H1299 cells (Figure 3C), on the other hand, overexpression of DPP10-AS1 dramatically decreased the early and late apoptosis in both two cell lines (Figure 3D). Collectively, DPP10-AS1-induced promotion of lung cancer cell growth appears to be mediated by cell cycle arrest at G2/M-phase and repression of apoptosis.

\section{DPP10-AS1 positively regulates DPP10 gene expression.}

DPP10-AS1 is a conserved 744-nt RNA transcribed from the antisense direction of the protein-coding gene DPP10 (2q14.1) (Figure 4A). To confirm the regulatory relationship between DPP10-AS1 and DPP10, we detected the expression levels of DPP10-AS1 and its sense-cognate gene DPP10. The results showed that knockdown of DPP10-AS1 reduced DPP10 gene expression at the mRNA (Figure 4B) and protein (Figure 4C) levels in both SPC-A1 and NCl-H1299 cells. On the contrary, overexpression of DPP10-AS1 enhanced DPP10 mRNA (Figure 4D) and protein (Figure 4E) expression in both lung cancer cell lines. To explore the effect of DPP10 on DPP10-AS1 expression in lung cancer cells, we used DPP10 siRNA and pcDNA3.1-DPP10 to inhibit and overexpress DPP10, respectively. The siRNA reduced the endogenous DPP10 gene expression at the mRNA (Additional File 2, Figure S2A) and protein (Additional File 2, Figure S2B) levels in both SPC-A1 and NCl-H1299 cells. In contrast, overexpression of DPP10 mediated by transfection of pcDNA3.1-DPP10 increased DPP10 gene expression at the mRNA (Additional File 2, Figure S2C) and protein (Additional File 2, Figure S2D) levels in both lung cancer cell lines. However, neither overexpression nor knockdown of DPP10 did not affect the expression of DPP10-AS1 in lung cancer cells (Figure 4F, G). These results suggest that the expression of DPP10 gene can be positively regulated by DPP10-AS1.

DPP10-AS1 and DPP10 are coordinately upregulated in lung cancer cells and tissues. 
Based on the positive regulation of DPP10 by DPP10-AS1, we also detected the expression of DPP10 mRNA in the same cohort of 94 paired lung cancer tissue samples using qRT-PCR. The results indicated that DPP10 expression in lung cancer tissues was significantly higher than that in corresponding adjacent tissues $(P<0.01$, Figure $5 \mathrm{~A}, \mathrm{~B})$. We also measured the $D P P 10$ expression in a panel of lung cancer cell lines, and found that there was an increase of DPP10 mRNA expression of in 4 lung cancer cell lines compared to human normal bronchial epithelial cells (BEAS-2B) (Figure 5C). Similarly, the protein expression of DPP10 was confirmed by Western blotting in lung cancer cells (Figure 5D). Moreover, the relative expression of DPP10 mRNA had a good positive correlation with DPP10-AS1 in lung cancer tissues $(r=0.7335, P<0.0001$, Figure $5 \mathrm{E})$ and lung cancer cell lines $(r=0.8737, P=0.0010$, Figure 5F). Together, these results indicate that the upregulation of DPP10-AS1 is coordinately correlated with DPP10 mRNA expression in lung cancer cell lines and in the tissues of lung cancer patients.

\section{DPP10-AS1 promotes malignant processes and inhibits apoptosis through upregulating DPP10 expression.}

To investigate whether the coordinate upregulation of DPP10-AS1 and DPP10 could affect malignant processes of lung cancer cells, we detected the cell behavior by overexpression of DPP-10 as well as knockdown of DPP10-AS1. In both SPC-A1 and NCI-H1299 cells, the MTT assays showed that knockdown of DPP10-AS1 inhibited lung cancer cell growth, while simultaneous overexpression of DPP10 could abolish the suppressive effect mediated by knockdown of DPP10-AS1 (Figure 6A). Conversely, overexpression of DPP10-AS1 promoted lung cancer cell growth, while simultaneous knockdown of DPP10 could abrogate the promotional effect mediated by overexpression of DPP10-AS1 (Figure 6B). Furthermore, the colony formation assays showed that the downregulated DPP10-AS1 inhibited the colony formation of lung cancer cells and overexpression of DPP 10 rescued the ability of colony formation in both SPC-A1 and NCl-H1299 cell lines (Figure 6C). In contrast, overexpression of DPP10-AS1 promoted the colony formation in SPC-A1 and NCI-H1299 cells, while knockdown of DPP10 abolished this promotional effect (Figure 6D). At the RNA level, overexpression of DPP10 could rescue the suppressive effect of downregulation of DPP10-AS1 on DPP10 mRNA, and knockdown of DPP10 could abolish the positive regulation of DPP10-AS1 on DPP10 mRNA in both two cell lines (Figure 6E). These results demonstrate that DPP10-AS1 affect cell growth and proliferation through regulating DPP10 mRNA expression.

In addition, cell cycle analysis showed that knockdown of DPP10-AS1 induced cell cycle arrest at G0/G1 phase and a decrease of cell population at G2/M phase, this effect was abolished by the overexpression of DPP10 in SPC-A1 and NCl-H1299 cells (Figure 7A). Meanwhile, overexpression of DPP10-AS1 resulted in a decrease of cell population at G0/G1 phase and cell cycle arrest at G2/M phase. However, this effect was also abolished by the depletion of DPP10 (Figure 7B). Furthermore, the apoptosis analysis showed that overexpression of DPP10 abolished the DPP10-AS1 knockdown-mediated increase of early and late apoptotic cells in both two lung cancer cell lines (Figure 7C). Conversely, the depletion of DPP10 rescued the DPP10-AS1 overexpression-mediated decrease of early and late apoptotic cells in lung cancer cells (Figure 7D). Collectively, the data suggests that DPP10-AS1 promotes cell growth and proliferation, 
induces cell cycle arrest and inhibits apoptosis through upregulating DPP10 gene expression in lung cancer cells.

\section{DPP10-AS1 associates with DPP10 mRNA but does not enhance DPP10 mRNA stability.}

To study whether DPP10-AS1 could enhance the stability of its sense-cognate gene DPP10, we determined the nucleoplasmic localization of DPP10-AS1. The nuclear and cytoplasmic fractionation analysis showed that DPP10-AS1 were mainly located in the nucleus (Figure 8A). Next, RNase protection assay was performed to examine the RNA duplex formation between DPP10-AS1 and DPP10 mRNA. The results showed that DPP10 mRNA was totally digested and no difference of protected DPP10 mRNA was found upon the conditions of DPP10-AS1 knockdown (Figure 8B) or DPP10-AS1 overexpression (Figure 8C), suggesting DPP10 mRNA cannot form RNA duplex with DPP10-AS1 to protect against RNase digestion. These results indicate DPP10-AS1 associates with DPP10 mRNA but does not enhance DPP10 mRNA stability by formation of RNA duplex.

\section{Hypomethylation of DPP10-AS1 and DPP10 contributes to their coordinate upregulation in lung cancer.}

To further reveal the underlying mechanism that contributes to the coordinate upregulation of DPP10-AS1 and DPP10 in lung cancer, we used the DNA methyltransferase inhibitor 5-azacytidine to determine the effect of methylation on the expression of DPP10-AS1 and DPP10. The results showed that the relative expression of DPP10-AS1 was remarkably upregulated with the increase of 5-azacytidine concentration in both SPC-A1 and NCl-H1299 cells (Figure 8D). Likewise, the relative expression of DPP10 mRNA was also significantly increased in a 5-azacytidine dose-dependent manner in the same two cell lines (Figure $8 \mathrm{E})$. These results suggest that hypomethylation of DPP10-AS1 and DPP10 may contribute to the coordinate upregulation of DPP10-AS1 and DPP10 in lung cancer. Interestingly, hypomethylation of DPP10 was found in lung adenocarcinoma (LUAD) patients compared to that in normal controls according to the LUAD dataset of the TCGA database (Figure 8F). Furthermore, one $\mathrm{CpG}$ island for DPP10-AS1 methylation and three CpG islands for DPP10 methylation were predicted by an epigenetic algorithm (Figure 8G). Taken together, the data indicate that the coordinate upregulation of DPP10- AS1 and DPP10 is epigenetically modulated by their hypomethylations, and the upregulation of DPP 10 positively regulated by DPP10-AS1 is a key event in lung cancer progression (Figure $\mathbf{8 H}$ ).

\section{Discussion}

It has now become widely accepted that mammalian genomes encode numerous IncRNAs[17]. Dysregulation of some IncRNAs has been shown in various type of cancers, including lung cancer[18, 19]. However, the functions and mechanisms behind antisense IncRNAs in lung cancer remain obscure. Based on our previous IncRNA microarray data, we identified a novel antisense IncRNA DPP10-AS1, was highly expressed in lung cancer tissues than that in adjacent noncancerous tissues. In addition, we explored the role of DPP10-AS1 in lung cancer malignant processes. We found the upregulation of DPP10-AS1 in cancer tissues was associated with serum CYFRA21-1 level, tumor size, TNM stage, RFS, as well as OS of the patients. It could be served as an independent prognostic factor for lung cancer patients. Moreover, in 
vitro experiments showed that inhibition of DPP10-AS1 could repress lung cancer cell proliferation and induce cell cycle arrest at G1/G0 phase and cell apoptosis. Thus, the data confirmed the hypothesis that as a novel IncRNA, DPP10-AS1 exerts tumor oncogenic activity to promote malignant processes in lung cancer. We also found that the hypo-methylation of both DPP10 and IncRNA DPP10-AS1 might contribute to their stabilization. Therefore, this study proved a novel insight into the role of DPP10-AS1 in lung cancer.

It is noteworthy some IncRNAs oriented in antisense direction with respect to a protein coding loci in the opposite strand usually act as regulators of their related genes[20-23]. Previous studies have shown that the natural antisense transcripts play critical roles in various physiological and pathological processes through regulating sense gene promoter activation and controlling mRNA stability and translatability[2427]. For example, natural antisense transcripts such as TFPI2AS1 and FOXC2-AS1 can bind the sense transcripts and alter the stability and expression of corresponding sense transcripts TFPI2 and FOXC2 $[28,29]$. Though natural antisense transcripts can bind the sense transcripts and change the stability and expression of corresponding sense transcripts, recent studies showed that upstream antisense transcription may function as a activator for corresponding gene expression[30, 31]. Dimitrova et al found that lincRNA p-21 acts as enhancer to the p21 promoter[32]. In our study, DPP10-AS1 is localized in the antisense DNA stand of the DPP10 gene. Therefore, we hypothesized that DPP10-AS1 might regulate DPP10 to contribute to progression of malignant diseases. Further experiments revealed the knockdown of DPP10-AS1 reduced DPP10 mRNA and protein expression in lung cancer cells, whereas overexpression of DPP10-AS1 increased DPP10 mRNA and protein expression. A considerable number of coding-gene promoters sustain divergent transcription of IncRNA/mRNA gene pairs[30]. The antisense transcription emanating from the bidirectional promoters have been shown to be involved in gene regulation[33]. Because of the nucleus location of DPP10-AS1, whether DPP10-AS1 regulates the activity of DPP10 promoter needs further investigation. In addition, DPP10 inhibition partially abrogated DPP10-AS1induced lung cancer cell growth, proliferation, cell cycle arrest at G1/G0 phase and apoptosis. While DPP10 overexpression showed an opposite effect in lung cancer cells. To reveal the actual mechanism underlying DPP10-AS1 affects DPP10 expression, we used an RNase protection assay to test the possibility of RNA duplex formation. However, the results show that DPP10-AS1 could not form RNA duplex with DPP10 mRNA and then to increase DPP10 mRNA stability. Thus, DPP10-AS1 promoting its sense gene DPP10 expression is probably caused by other modifications or regulations.

DNA methylation is an epigenetic modification that plays a key role in transcriptional regulation and associated with most human malignancies[34, 35]. It has been found that genome-wide early hypomethylation seems to affect both protein coding and long noncoding regions of the genome[36, 37]. The hypomethylation of noncoding DNA regions resulted in the overexpression of IncRNA AFAP1-AS1 and correlated with esophageal adenocarcinoma progression[38]. Genome-wide screen identified the differentially methylated Esrp2-as which was significantly upregulated in human breast cancer and associated with poor prognosis[39]. In the current study, we found that both DPP10-AS1 and DPP10 were coordinately methylated using the treatment with 5-azacytidine. Interestingly, DPP10 methylation level in lung squamous cell carcinoma was significantly lower than that in healthy controls from the methylation 
database (MethHC). Furthermore, computational analysis predicted three $\mathrm{CpG}$ islands in the promoter of DPP10, as well as one CpG island in DPP10-AS1 spanning the transcription initiation site. These results indicate that differential methylations of DPP10-AS1 and DPP10 may be responsible for their coordinate upregulation in lung cancer.

The recent application of next-generation sequencing (NGS) to a growing number of cancer transcriptomes has indeed revealed thousands of IncRNAs whose aberrant expression is associated with different cancer types. Among the few that have been functionally characterized, several have been linked to malignant transformation. Notably, these IncRNAs have key roles in gene regulation and thus affect various aspects of cellular behaviors, including differentiation, proliferation, invasion, migration or genomic stability[40]. In addition, the highly expressed IncRNAs function as oncogenes to activate oncogenic signal pathways and promote the carcinogenesis[41-43]. Importantly, the potential values of IncRNAs in cancer diagnosis, prognosis and targeted therapy has been also shown[14, 44, 45]. Interestingly, DPP10 was originally identified as prognostic marker and a therapeutic gene in cancer patients $[46,47]$. However, the potential regulatory mode and carcinogenic mechanism of DPP10 in cancers remain unclear. Here, we demonstrate that DPP10-AS1 acts as a positive regulator of DPP10, which in turn exerts an oncogenic effect. In this study, we evaluated the biological function of DPP10-AS1 in lung cancer. DPP10-AS1 is widely involved in lung cancer pathophysiology by increasing cell growth, proliferation, promoting cell cycle progression, and inhibiting apoptosis. Meanwhile, the data indicate that DPP10-AS1 is an independent prognostic predictor for both overall survival and recurrence-free survival, suggesting the potential role of DPP10-AS1 in lung cancer diagnosis and prognosis. However, the molecular mechanism underlying the physical interaction of DPP10-AS1 and DPP10 gene needs further investigation for better understanding of IncRNA DPP10-AS1 in lung carcinogenesis.

\section{Conclusions}

In summary, we identified a novel IncRNA DPP10-AS1, which was highly expressed in lung cancer and the upregulation of DPP10-AS1 predicted poor prognosis in lung cancer patients. Notably, knockdown of DPP10-AS1 could inhibit cell proliferation, promote cell cycle progression and trigger early and late apoptosis. Whereas overexpression of DPP10-AS1 showed the opposite effects. Importantly, DPP10-AS1 promoted the lung cancer malignant processes by positively regulating DPP10 gene expression. The coordinate upregulation of DPP10-AS1 and DPP10 is mediated by epigenetically hypomethylation. Collectively, these findings provide novel insights into DPP10-AS1 as a candidate prognostic biomarker and as a potential therapeutic target in lung cancer.

\section{Declarations}

\section{Ethics approval and consent to participate}

Human lung primary cancer tissue specimens and cancer-adjacent tissues were collected from the patients underwent the radical surgery of lung cancer or palliative resection of lung cancer at the 
Affiliated Hospital of Medical School of Ningbo University and Ningbo Medical Center Lihuili Eastern Hospital. Written informed consent was obtained from all patients and the study protocol was approved by the Clinical Research Ethics Committee of Medical School of Ningbo University. All methods were performed in accordance with relevant guidelines and local regulations.

\section{Consent for publication}

Not applicable.

\section{Availability of data and material}

The authors declare that all the other data supporting the findings of this study are available within the article and its additional files and from the corresponding author upon reasonable request.

\section{Competing interests}

The authors have no conflicts of interest to disclose.

\section{Funding}

This work was supported in part by research grants from the Non-profit Technology Research Program of Zhejiang (LGF18H160006), the Natural Science Foundation of Zhejiang (LQ18H200001), the Non-profit Technology Research Program of Ningbo (2019C50040), the Natural Science Foundation of Ningbo (2018A610204), the Scientific Innovation Team Project of Ningbo (2017C110019) and the K.C. Wong Magna Fund in Ningbo University. The above funding body has no role in the design of the study and collection, analysis, and interpretation of data and in writing the manuscript.

\section{Author Contributions}

Z.G. and H.T. developed the concepts for the manuscript and designed the study. H.T., J.P., and S.F. performed the qRT-PCR, Western blot, xenograft animal experiments. C.Z., H.T., J.H., and W.S. collected the clinical samples and performed the clinicopathologic analyses. H.T., Z.G., X.M., and X.J. performed the data analysis and discussed results. H.T. prepared the manuscript and all authors contributed to editing the paper.

\section{Acknowledgements}

We thank Dr. Xiaodong Zhao (The Affiliated Hospital of Medical School of Ningbo University) for the pathological analysis of clinical samples.

\section{Abbreviations}

DMEM: Dulbecco's modified Eagle's medium; HOTAIR: Hox transcript antisense intergenic RNA; IncRNA: Long noncoding RNA; MALAT1: metastasis-associated lung adenocarcinoma transcript 1; NGS: next- 
generation sequencing; OS: Overall survival; RFS: qRT-PCR: quantitative reverse transcription polymerase chain reaction; RFS: Recurrence-free survival.

\section{References}

1. Mercer TR, Dinger ME, Mattick JS: Long non-coding RNAs: insights into functions.Nat Rev Genet 2009, 10:155-159.

2. Ponting CP, Oliver PL, Reik W: Evolution and functions of long noncoding RNAs.Cell 2009, 136:629641.

3. Gibb EA, Brown CJ, Lam WL: The functional role of long non-coding RNA in human carcinomas.Mol Cancer 2011, 10:38.

4. Li J, Tian H, Yang J, Gong Z: Long Noncoding RNAs Regulate Cell Growth, Proliferation, and Apoptosis.DNA Cell Biol 2016, 35:459-470.

5. Peng WX, Koirala P, Mo YY: LncRNA-mediated regulation of cell signaling in cancer.Oncogene 2017, 36:5661-5667.

6. Sun Q, Hao Q, Prasanth KV: Nuclear Long Noncoding RNAs: Key Regulators of Gene Expression. Trends Genet 2018, 34:142-157.

7. Liao XH, Wang JG, Li LY, Zhou DM, Ren KH, Jin YT, Lv L, Yu JG, Yang JY, Lu Q, et al: Long intergenic non-coding RNA APOC1P1-3 inhibits apoptosis by decreasing alpha-tubulin acetylation in breast cancer.Cell Death Dis 2016, 7:e2236.

8. Yuan JH, Yang F, Wang F, Ma JZ, Guo YJ, Tao QF, Liu F, Pan W, Wang TT, Zhou CC, et al: A long noncoding RNA activated by TGF-beta promotes the invasion-metastasis cascade in hepatocellular carcinoma.Cancer Cel/ 2014, 25:666-681.

9. Wang R, Shi Y, Chen L, Jiang Y, Mao C, Yan B, Liu S, Shan B, Tao Y, Wang X: The ratio of FoxA1 to FoxA2 in lung adenocarcinoma is regulated by LncRNA HOTAIR and chromatin remodeling factor LSH.Sci Rep 2015, 5:17826.

10. Gutschner T, Hammerle M, Eissmann M, Hsu J, Kim Y, Hung G, Revenko A, Arun G, Stentrup M, Gross $\mathrm{M}$, et al: The noncoding RNA MALAT1 is a critical regulator of the metastasis phenotype of lung cancer cells.Cancer Res 2013, 73:1180-1189.

11. Su W, Feng S, Chen X, Yang X, Mao R, Guo C, Wang Z, Thomas DG, Lin J, Reddy RM, et al: Silencing of long non-coding RNA MIR22HG triggers cell survival/death signaling via oncogenes YBX1, MET, and p21 in lung cancer.Cancer Res 2018.

12. Moran VA, Perera RJ, Khalil AM: Emerging functional and mechanistic paradigms of mammalian long non-coding RNAs.Nucleic Acids Res 2012, 40:6391-6400.

13. Li W, Sun M, Zang C, Ma P, He J, Zhang M, Huang Z, Ding Y, Shu Y: Upregulated long non-coding RNA AGAP2-AS1 represses LATS2 and KLF2 expression through interacting with EZH2 and LSD1 in nonsmall-cell lung cancer cells. Cell Death Dis 2016, 7:e2225. 
14. Jiang N, Meng X, Mi H, Chi Y, Li S, Jin Z, Tian H, He J, Shen W, Tian H, et al: Circulating IncRNA XLOC_009167 serves as a diagnostic biomarker to predict lung cancer.Clin Chim Acta 2018, 486:2633.

15. Yang L, Yang J, Li J, Shen X, Le Y, Zhou C, Wang S, Zhang S, Xu D, Gong Z: MircoRNA-33a inhibits epithelial-to-mesenchymal transition and metastasis and could be a prognostic marker in non-small cell lung cancer.Sci Rep 2015, 5:13677.

16. Li J, Tian H, Pan J, Jiang N, Yang J, Zhou C, Xu D, Meng X, Gong Z: Pecanex functions as a competitive endogenous RNA of S-phase kinase associated protein 2 in lung cancer.Cancer Lett 2017, 406:36-46.

17. Guttman M, Amit I, Garber M, French C, Lin MF, Feldser D, Huarte M, Zuk O, Carey BW, Cassady JP, et al: Chromatin signature reveals over a thousand highly conserved large non-coding RNAs in mammals.Nature 2009, 458:223-227.

18. Li K, Sun D, Gou Q, Ke X, Gong Y, Zuo Y, Zhou JK, Guo C, Xia Z, Liu L, et al: Long non-coding RNA linc00460 promotes epithelial-mesenchymal transition and cell migration in lung cancer cells.Cancer Lett 2018, 420:80-90.

19. Sun Y, Hu B, Wang Q, Ye M, Qiu Q, Zhou Y, Zeng F, Zhang X, Guo Y, Guo L: Long non-coding RNA HOTTIP promotes BCL-2 expression and induces chemoresistance in small cell lung cancer by sponging miR-216a.Cell Death Dis 2018, 9:85.

20. Chen N, Guo D, Xu Q, Yang M, Wang D, Peng M, Ding Y, Wang S, Zhou J: Long non-coding RNA FEZF1-AS1 facilitates cell proliferation and migration in colorectal carcinoma.Oncotarget 2016, 7:11271-11283.

21. Huang B, Song JH, Cheng Y, Abraham JM, Ibrahim S, Sun Z, Ke X, Meltzer SJ: Long non-coding antisense RNA KRT7-AS is activated in gastric cancers and supports cancer cell progression by increasing KRT7 expression. Oncogene 2016, 35:4927-4936.

22. Sun J, Wang X, Fu C, Wang X, Zou J, Hua H, Bi Z: Long noncoding RNA FGFR3-AS1 promotes osteosarcoma growth through regulating its natural antisense transcript FGFR3.Mol Biol Rep 2016, 43:427-436.

23. Liu C, Lin J: Long noncoding RNA ZEB1-AS1 acts as an oncogene in osteosarcoma by epigenetically activating ZEB1.Am J Trans/ Res 2016, 8:4095-4105.

24. Vadaie $\mathrm{N}$, Morris KV: Long antisense non-coding RNAs and the epigenetic regulation of gene expression.Biomol Concepts 2013, 4:411-415.

25. Villegas VE, Zaphiropoulos PG: Neighboring gene regulation by antisense long non-coding RNAs.Int J Mol Sci 2015, 16:3251-3266.

26. Carrieri C, Cimatti L, Biagioli M, Beugnet A, Zucchelli S, Fedele S, Pesce E, Ferrer I, Collavin L, Santoro $\mathrm{C}$, et al: Long non-coding antisense RNA controls Uchl1 translation through an embedded SINEB2 repeat.Nature 2012, 491:454-457.

27. Yuan SX, Tao QF, Wang J, Yang F, Liu L, Wang LL, Zhang J, Yang Y, Liu H, Wang F, et al: Antisense long non-coding RNA PCNA-AS1 promotes tumor growth by regulating proliferating cell nuclear 
antigen in hepatocellular carcinoma.Cancer Lett 2014, 349:87-94.

28. Gao S, Lin Z, Li C, Wang Y, Yang L, Zou B, Chen J, Li J, Song Z, Liu G: TFPI2AS1, a novel IncRNA that inhibits cell proliferation and migration in lung cancer.Cell Cycle 2017, 16:2249-2258.

29. Zhang CL, Zhu KP, Ma XL: Antisense IncRNA FOXC2-AS1 promotes doxorubicin resistance in osteosarcoma by increasing the expression of FOXC2.Cancer Lett 2017, 396:66-75.

30. Lepoivre C, Belhocine M, Bergon A, Griffon A, Yammine M, Vanhille L, Zacarias-Cabeza J, Garibal MA, Koch $F$, Maqbool MA, et al: Divergent transcription is associated with promoters of transcriptional regulators.BMC Genomics 2013, 14:914.

31. Kurihara M, Shiraishi A, Satake H, Kimura AP: A conserved noncoding sequence can function as a spermatocyte-specific enhancer and a bidirectional promoter for a ubiquitously expressed gene and a testis-specific long noncoding RNA.J Mol Biol 2014, 426:3069-3093.

32. Dimitrova N, Zamudio JR, Jong RM, Soukup D, Resnick R, Sarma K, Ward AJ, Raj A, Lee JT, Sharp PA, Jacks T: LincRNA-p21 activates p21 in cis to promote Polycomb target gene expression and to enforce the G1/S checkpoint.Mol Cel/ 2014, 54:777-790.

33. Wei W, Pelechano V, Jarvelin Al, Steinmetz LM: Functional consequences of bidirectional promoters. Trends Genet 2011, 27:267-276.

34. Nebbioso A, Tambaro FP, Dell'Aversana C, Altucci L: Cancer epigenetics: Moving forward.PLoS Genet 2018, 14:e1007362.

35. Rhee I, Bachman KE, Park BH, Jair KW, Yen RW, Schuebel KE, Cui H, Feinberg AP, Lengauer C, Kinzler KW, et al: DNMT1 and DNMT3b cooperate to silence genes in human cancer cells.Nature 2002, 416:552-556.

36. Subhash S, Andersson PO, Kosalai ST, Kanduri C, Kanduri M: Global DNA methylation profiling reveals new insights into epigenetically deregulated protein coding and long noncoding RNAs in CLL.Clin Epigenetics 2016, 8:106.

37. Yao X, Xing M, Ooi WF, Tan P, Teh BT: Epigenomic Consequences of Coding and Noncoding Driver Mutations.Trends Cancer 2016, 2:585-605.

38. Wu W, Bhagat TD, Yang X, Song JH, Cheng Y, Agarwal R, Abraham JM, Ibrahim S, Bartenstein M, Hussain Z, et al: Hypomethylation of noncoding DNA regions and overexpression of the long noncoding RNA, AFAP1-AS1, in Barrett's esophagus and esophageal adenocarcinoma.Gastroenterology 2013, 144:956-966 e954.

39. Heilmann K, Toth R, Bossmann C, Klimo K, Plass C, Gerhauser C: Genome-wide screen for differentially methylated long noncoding RNAs identifies Esrp2 and IncRNA Esrp2-as regulated by enhancer DNA methylation with prognostic relevance for human breast cancer.Oncogene 2017, 36:6446-6461.

40. Huarte M: The emerging role of IncRNAs in cancer.Nat Med 2015, 21:1253-1261.

41. Panda S, Setia M, Kaur N, Shepal V, Arora V, Singh DK, Mondal A, Teli A, Tathode M, Gajula R, et al: Noncoding RNA Ginir functions as an oncogene by associating with centrosomal proteins. PLOS Biol 2018, 16:e2004204. 
42. Schmitt AM, Chang HY: Long Noncoding RNAs in Cancer Pathways.Cancer Cel/ 2016, 29:452-463.

43. Xu TP, Wang WY, Ma P, Shuai Y, Zhao K, Wang YF, Li W, Xia R, Chen WM, Zhang EB, Shu YQ: Upregulation of the long noncoding RNA FOXD2-AS1 promotes carcinogenesis by epigenetically silencing EphB3 through EZH2 and LSD1, and predicts poor prognosis in gastric cancer.Oncogene 2018, 37:5020-5036.

44. Qi P, Zhou XY, Du X: Circulating long non-coding RNAs in cancer: current status and future perspectives.Mol Cancer 2016, 15:39.

45. Yang Z, Li X, Yang Y, He Z, Qu X, Zhang Y: Long noncoding RNAs in the progression, metastasis, and prognosis of osteosarcoma.Cell Death Dis 2016, 7:e2389.

46. Park HS, Yeo HY, Chang HJ, Kim KH, Park JW, Kim BC, Baek JY, Kim SY, Kim DY: Dipeptidyl peptidase 10, a novel prognostic marker in colorectal cancer. Yonsei Med J 2013, 54:1362-1369.

47. Hu B, Shi C, Jiang HX, Qin SY: Identification of novel therapeutic target genes and pathway in pancreatic cancer by integrative analysis.Medicine (Baltimore) 2017, 96:e8261.

\section{Tables}

Table 1 Correlations between DPP10-AS1 and clinical characteristics of 94 lung cancer patients.

\begin{tabular}{|c|c|c|c|c|c|}
\hline \multirow[b]{2}{*}{ Characteristics } & \multirow[t]{2}{*}{$\mathrm{n}$} & \multicolumn{2}{|c|}{ DPP10-AS1 levels $†$} & \multirow[t]{2}{*}{$\chi^{2}$ text } & \multirow[t]{2}{*}{ P value } \\
\hline & & Low & High & & \\
\hline $\begin{array}{l}\text { Total cases } \\
\text { Gender }\end{array}$ & 94 & 47 & 47 & & \\
\hline $\begin{array}{c}\text { Male } \\
\text { Female }\end{array}$ & $\begin{array}{l}46 \\
48\end{array}$ & $\begin{array}{l}27 \\
20\end{array}$ & $\begin{array}{l}19 \\
28\end{array}$ & 2.725 & 0.0988 \\
\hline Age(years) & & & & & \\
\hline $\begin{array}{r}\leq 55 \\
\square 55\end{array}$ & $\begin{array}{l}34 \\
60\end{array}$ & $\begin{array}{l}14 \\
31\end{array}$ & $\begin{array}{l}20 \\
29\end{array}$ & 0.9570 & 0.3279 \\
\hline $\begin{array}{c}\text { Serum CYFRA21-1 } \\
\leq 3.3 \\
\square 3.3\end{array}$ & $\begin{array}{l}50 \\
46\end{array}$ & $\begin{array}{l}32 \\
17\end{array}$ & $\begin{array}{l}18 \\
27\end{array}$ & 6.033 & $0.0140 *$ \\
\hline $\begin{array}{c}\text { Tumor number } \\
\text { Single } \\
\text { Multiple }\end{array}$ & $\begin{array}{l}72 \\
22\end{array}$ & $\begin{array}{l}39 \\
8\end{array}$ & $\begin{array}{l}33 \\
14\end{array}$ & 2.136 & 0.1438 \\
\hline $\begin{array}{c}\text { Tumor size }(\mathrm{cm}) \\
\leq 5 \\
\square 5\end{array}$ & $\begin{array}{l}64 \\
30\end{array}$ & $\begin{array}{l}38 \\
9\end{array}$ & $\begin{array}{l}26 \\
21\end{array}$ & 7.050 & $0.0079 * *$ \\
\hline $\begin{array}{c}\text { TNM stage } \\
\square / \square \\
\square \\
\text { Microvascular invasion }\end{array}$ & $\begin{array}{l}65 \\
29\end{array}$ & $\begin{array}{l}35 \\
9\end{array}$ & $\begin{array}{l}30 \\
20\end{array}$ & 4.191 & $0.0406 *$ \\
\hline $\begin{array}{l}\text { Present } \\
\text { Absent }\end{array}$ & $\begin{array}{l}36 \\
58\end{array}$ & $\begin{array}{l}17 \\
32\end{array}$ & $\begin{array}{l}19 \\
26\end{array}$ & 0.5626 & 0.4532 \\
\hline $\begin{array}{c}\text { Yes } \\
\text { No }\end{array}$ & $\begin{array}{l}44 \\
50\end{array}$ & $\begin{array}{l}18 \\
27\end{array}$ & $\begin{array}{l}26 \\
23\end{array}$ & 1.607 & 0.2049 \\
\hline
\end{tabular}


†Median expression level was used as cutoff. Low expression of DPP10-AS1 in 94 patients was defined as a value below the 50th percentile, and high above the 50th percentile. $P$ values were acquired by Pearson's chisquare test. $* P<0.05, * * P<0.01$.

Table 2 Univariate and multivariate analysis of clinicopathological variables for RFS rates in 94 patients with lung cancer.

\begin{tabular}{|c|c|c|c|c|c|c|}
\hline \multirow[b]{2}{*}{ Variables } & \multicolumn{3}{|c|}{ Univariate analysis } & \multicolumn{3}{|c|}{ Multivariate analysis } \\
\hline & Pvalue & HIR & $95 \% \mathrm{CI}$ & $P$ value & HR & $95 \% \mathrm{CI}$ \\
\hline Gender (male vs. female) & 0.324 & 1.036 & $0.575-1.686$ & & & \\
\hline Age ( $\square 55$ vs. $\leq 55$ y & 0.431 & 1.231 & $0.787-2.325$ & & & \\
\hline Serum CYFR1 ( $\square 3.3$ vs. $\leq 3.3 n g$ & 0.336 & 0.957 & $0.794-3.240$ & & & \\
\hline no hictory (yo vo no) & 0.759 & 1.325 & $0.885-3.945$ & & & \\
\hline umber (single vs. multiple) & 0.576 & 1.695 & $0.759-5.621$ & & & \\
\hline ion (present vs. absen & 0.042 & 2.168 & $1.285-4.326$ & & & \\
\hline 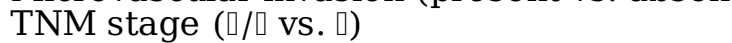 & 0.036 & 0.413 & $0.226-0.894$ & & & \\
\hline$(\square 5 \mathrm{~cm}$ vs. $\leq 5 \mathrm{~cm})$ & 0.021 & 2.186 & $1.273-4.536$ & 0.032 & 2.304 & 1.219-3.947 \\
\hline DPP10-AS1 expression (higher vs. lower) & 0.009 & 2.84 & $1.363-5.975$ & 0.012 & .446 & 823 \\
\hline
\end{tabular}

RFS, recurrence-free survival; HR, hazard ratio; CI, confidence interval.

Table 3 Univariate and multivariate analysis of clincopathological variables for OS rates in 94 patients with lung cancer.

\begin{tabular}{|c|c|c|c|c|c|c|}
\hline \multirow[b]{2}{*}{ Variables } & \multicolumn{3}{|c|}{ Univariate analysis } & \multicolumn{3}{|c|}{ Multivariate analysis } \\
\hline & $P$ value & HR & $95 \% \mathrm{CI}$ & $P$ value & HR & $95 \% \mathrm{CI}$ \\
\hline Gender (male vs. female) & 0.527 & 1.196 & $0.687-2.080$ & & & \\
\hline Age ( $₫ 55$ vs. $\leq 55$ years) & 0.921 & 1.001 & $0.976-1.028$ & & & \\
\hline CYFR1 ( $(3.3$ vs. $\leq 3.3 \mathrm{ng} / \mathrm{ml})$ & 0.405 & 0.759 & $0.398-1.450$ & & & \\
\hline Smoking history (yes vs. no) & 0.302 & 1.526 & $0.684-3.405$ & & & \\
\hline Microvascular invasion (pr & 0.546 & 1.156 & $0.789-2.123$ & & & \\
\hline Tumor number (single vs. multiple) & 0.865 & 1.191 & $0.159-8.932$ & & & \\
\hline$(\square 5 \mathrm{~cm}$ vs. $\leq 5 \mathrm{~cm})$ & 0.008 & 3.382 & $1.374-8.330$ & 0.652 & 1.304 & $0.411-4$ \\
\hline re (口/ vs. $\square$ ) & $<0.001$ & 0.313 & $0.114-0.899$ & 0.037 & 3.166 & 1.07 \\
\hline DPP10-AS 1 expression (high & 0.019 & 2.55 & $1.167-5.572$ & 0.016 & 2.765 & $1.212-6.307$ \\
\hline
\end{tabular}


OS, overall survival; HR, hazard ratio; CI, confidence interval.

\section{Figures}

A

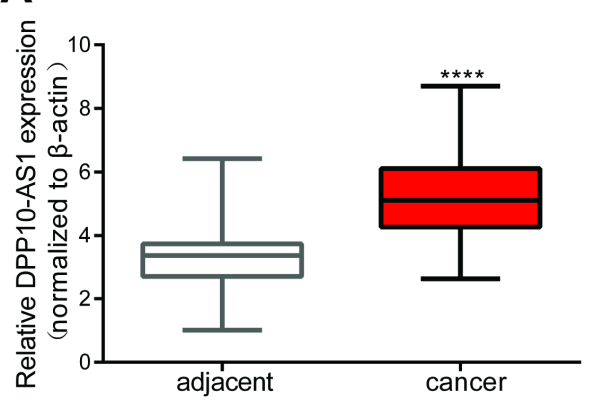

D

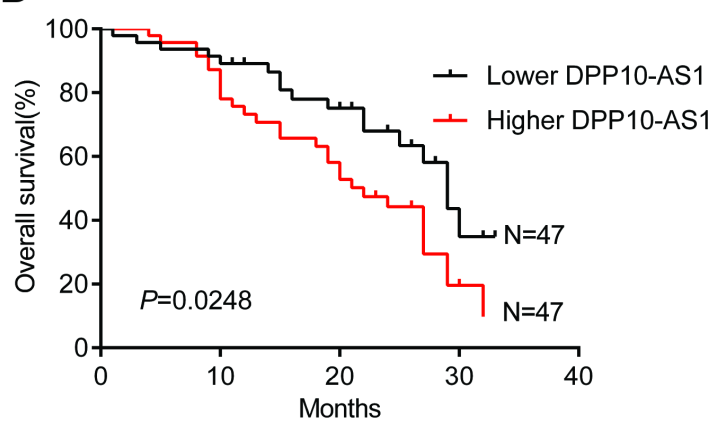

B

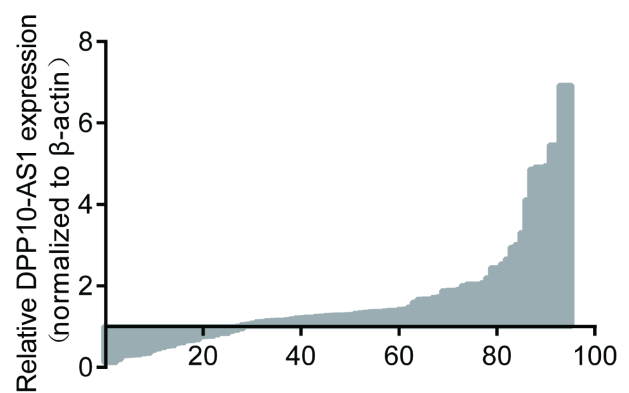

E

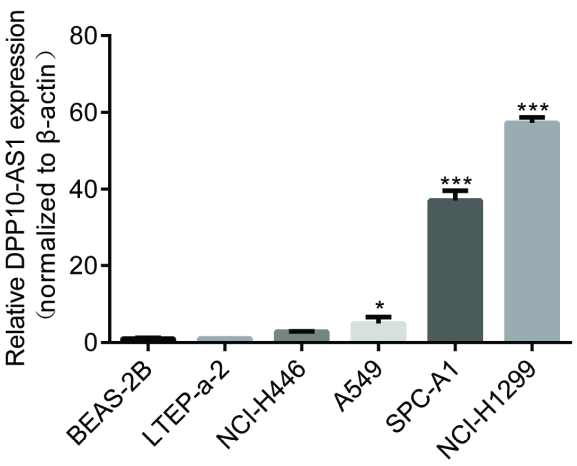

Figure 1

The upregulated DPP10-AS1 predicts poor prognosis in lung cancer patients. (A) DPP10-AS1 expression in lung cancer tissues and corresponding noncancerous lung tissues was measured by qRT-PCR and normalized to $\beta$-actin. The horizontal lines in the box plots represent the medians. The boxes represent the interquartile range, and the whiskers represent the 2.5th and 97.5th percentiles. Statistical differences between groups were compared using the Wilcoxon signed-rank test $(n=94, P<0.0001)$. (B) The ratio between the relative quantification of DPP10-AS1 expression in lung cancer tissues vs. paired adjacent noncancerous lung tissues of each case. Kaplan-Meier survival analyses of the correlation between DPP10-AS1 expression level and recurrence-free survival (C) or overall survival (D) of 94 lung cancer patients. The median expression level was used as cutoff. Statistical significances were analyzed using the log-rank test. (E) DPP10-AS1 expression in a normal lung epithelial cell line (BEAS-2B) and in 5 lung cancer cell lines (NCI-H446, A549, LTEP-a-2, SPC-A1, NCl-H1299). Data are shown as mean \pm standard error based on at least three independent experiments. ${ }^{\star} P<0.05$, ${ }^{\star \star \star} P<0.001$, ${ }^{\star \star \star \star} P<0.0001$. 

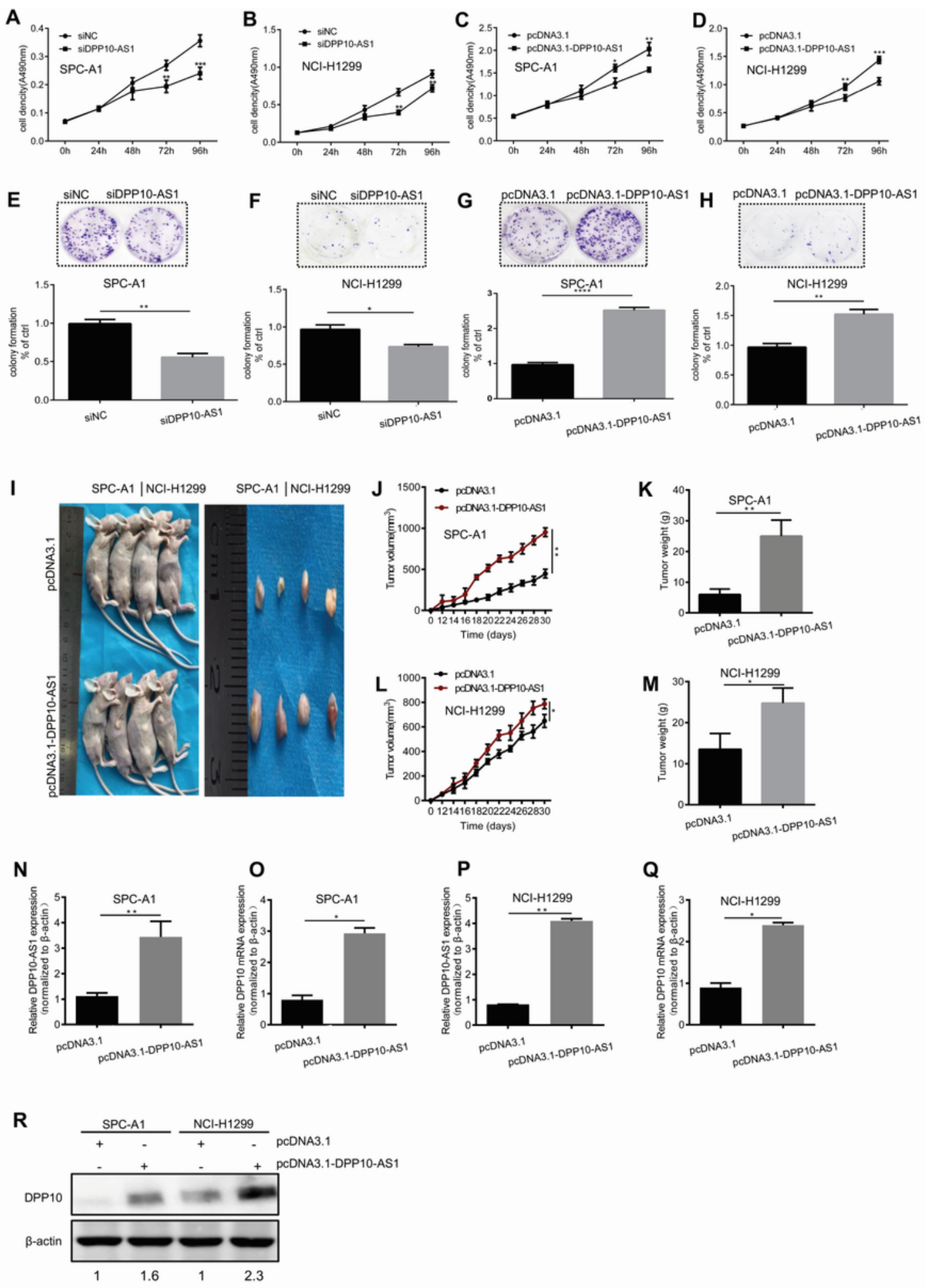

Figure 2

DPP10-AS1 promotes lung cancer cell proliferation in vitro and tumor growth in vitro. MTT assays were performed to determine the viability of lung cancer cells treated with siDPP10-AS1 in SPC-A1 (A) and NCl$\mathrm{H} 1299$ (B) cells, and with pcDNA3.1-DPP10-AS1 in SPC-A1 (C) and NCl-H1299 (D) cells. Colony formation assays were used to detect the proliferation abilities of lung cancer cells after transfection of siDPP10AS1 in SPC-A1 (E) and NCl-H1299 (F) cells, and of pcDNA3.1-DPP10-AS1 in SPC-A1 (G) and NCl-H1299 
$(\mathrm{H})$ cells. Lung cancer cells overexpressing pcDNA3.1-DPP10-AS1 were injected subcutaneously into nude mice to show the xenograft tumor growth (I). Analysis of tumor volume $(\mathrm{J})$ and tumor weight $(\mathrm{K})$ in SPCA1 cells with overexpression of pcDNA3.1-DPP10-AS1. Analysis of tumor volume (L) and tumor weight (M) in NCl-H1299 cells with overexpression of pcDNA3.1-DPP10-AS1. RT-qPCR analysis of IncRNA DPP10-AS1 (N) and DPP10 mRNA (0) expression in tumor tissues post-injection of in SPC-A1 cells. RTqPCR analysis of IncRNA DPP10-AS1 (P) and DPP10 mRNA (Q) expression in tumor tissues postinjection of $\mathrm{NCl}-\mathrm{H} 1299$ cells. Western blot assays of DPP10 protein in tumor tissues overexpressing IncRNA DPP10-AS1 and empty plasmid group (R). Colonies were counted and captured. The bars charts statistically compared the differences of colony formation in each experimental group compared to the corresponding control. Values are shown as the mean $\pm S D$ in three independent experiments. ${ }^{*}<<0.05$, ${ }^{\star} * \mathrm{P}<0.01,{ }^{\star \star *} \mathrm{P}<0.001$, ${ }^{\star \star \star *} \mathrm{P}<0.0001$. 
A

A sinc SiDPP10-AS1

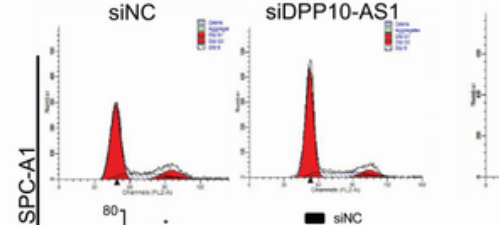

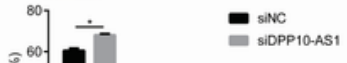

每

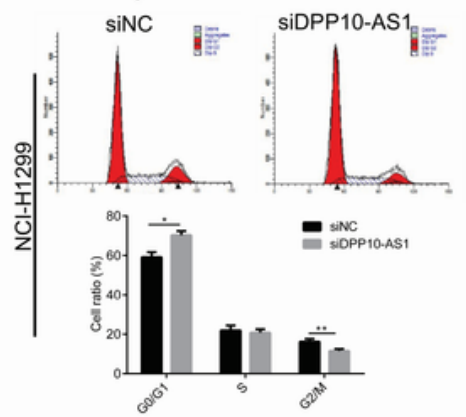

C

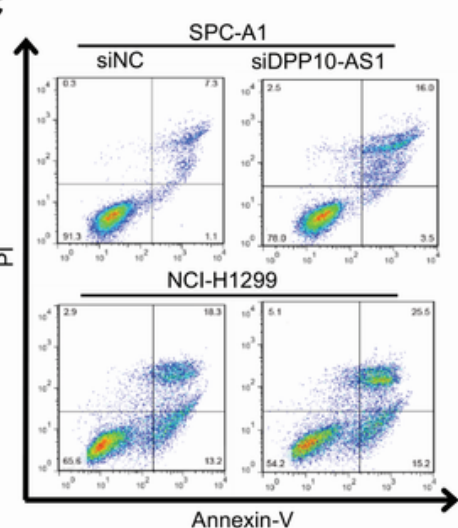

D

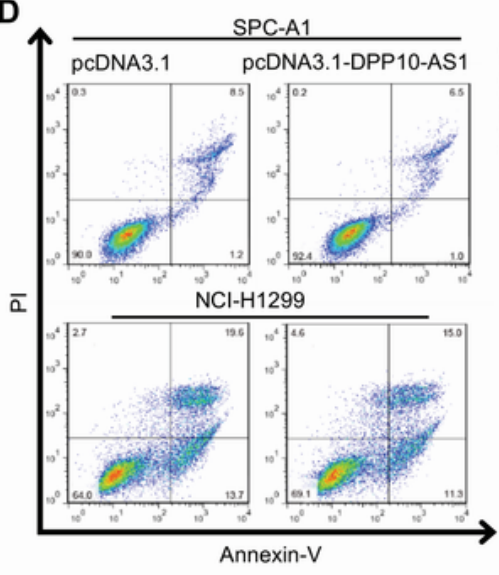

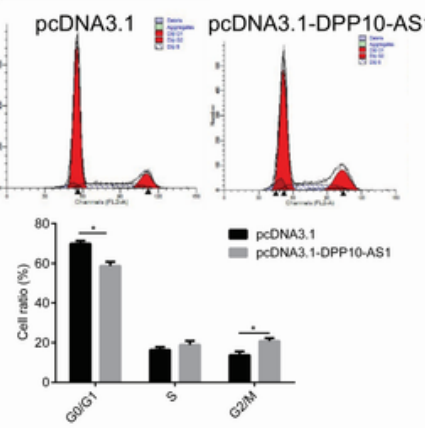
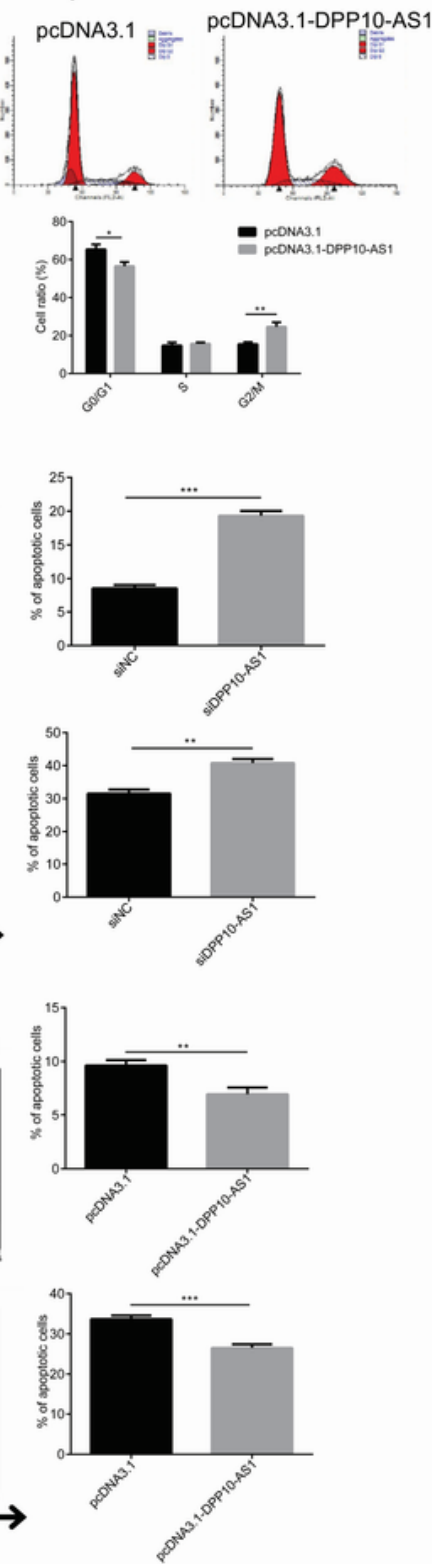

Figure 3

DPP10-AS1 promotes cell cycle progression and inhibits apoptosis of lung cancer cells. SPC-A1 and NCIH1299 lung cancer cells were treated with siDPP10-AS1 (A) or pcDNA3.1-DPP10-AS1 (B) and then were analyzed for cell cycle by flow cytometry. After the knockdown of DPP10-AS1 (C) or overexpression of DPP10-AS1 (D), lung cancer cell apoptosis was analyzed by flow cytometry using Annexin V/PI staining. The data are presented as the mean \pm SD $(n=3)$, and ${ }^{*} P<0.05, * * P<0.01, * * * P<0.001$. 
A

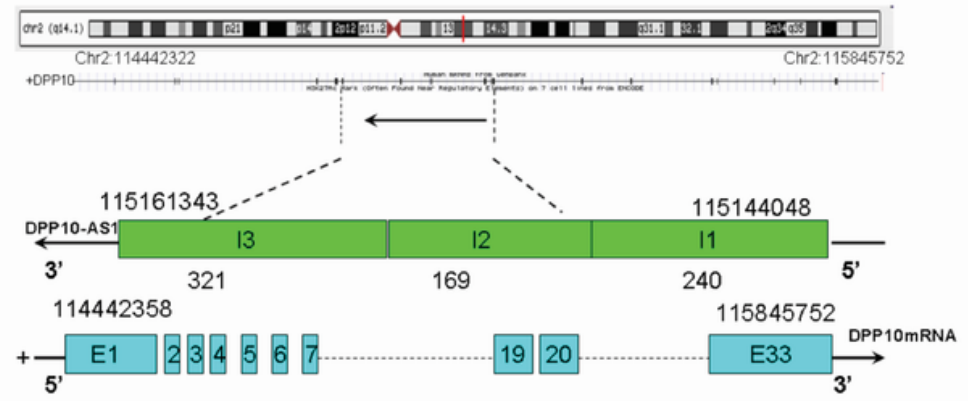

C

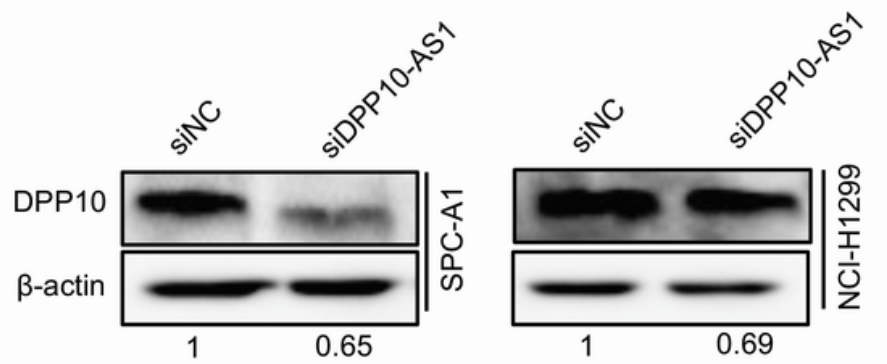

E

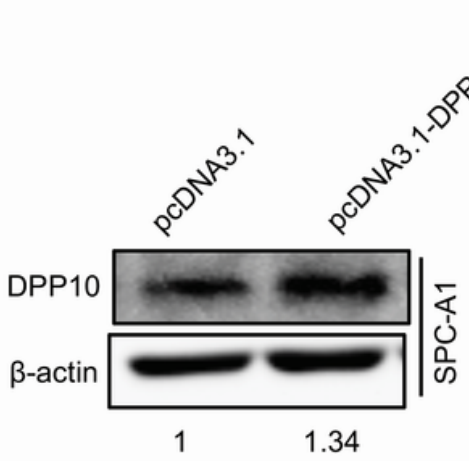

G

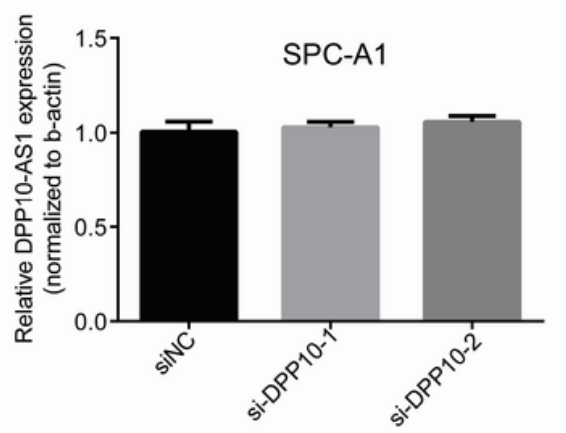

B
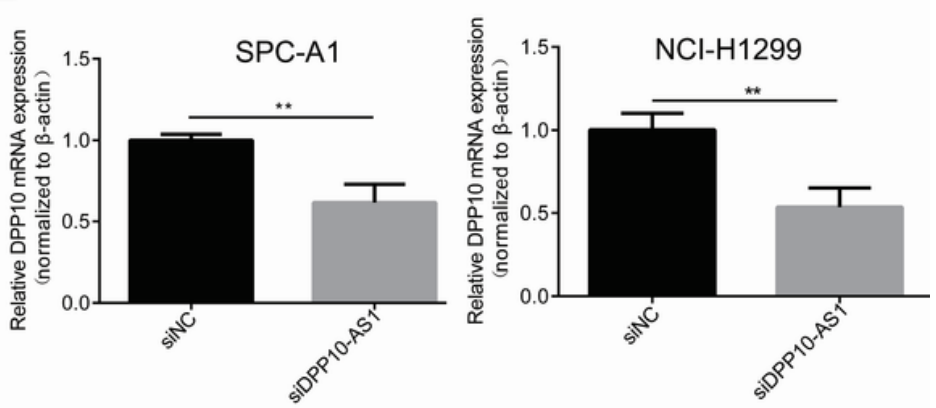

D
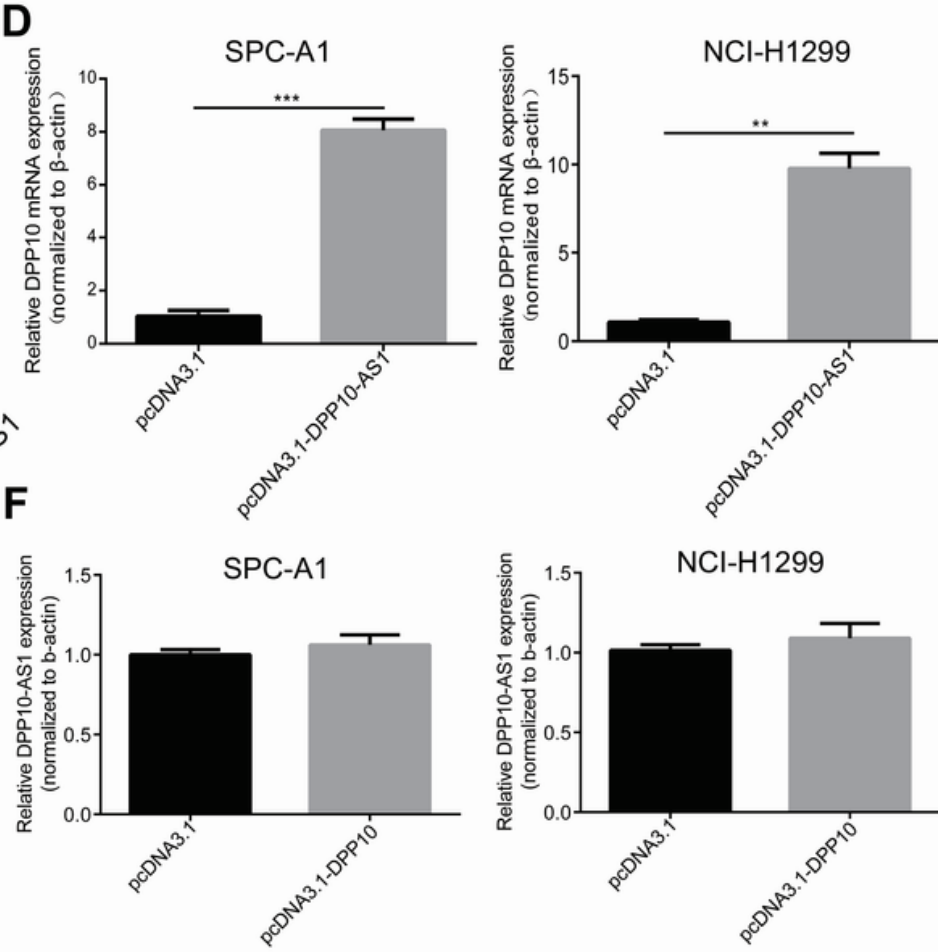

\section{Figure 4}

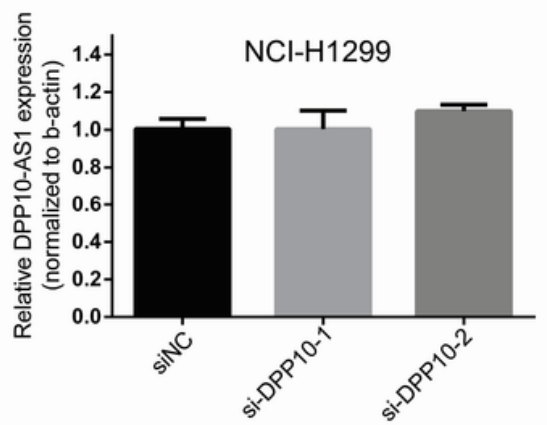

DPP10-AS1 positively regulates DPP10. (A) Genetic structure diagram of DPP10-AS1. (B) Effect of DPP10-AS1 knockdown on DPP10 mRNA. (C) Effect of DPP10-AS1 overexpression on DPP10 protein. (D) Effect of DPP10 overexpression on DPP10 mRNA. (E) Effect of DPP10-AS1 overexpression on DPP10 protein. (F) Effect of DPP10 overexpression on DPP10-AS1. (G) Effect of DPP10 knockdown on DPP10AS1. Data are shown as mean \pm SD based on three independent experiments. ${ }^{\star \star} P<0.01,{ }^{* \star *} P<0.001$. 
A

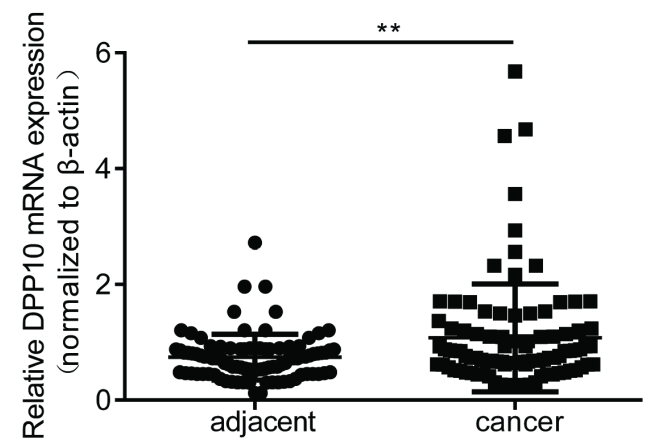

D

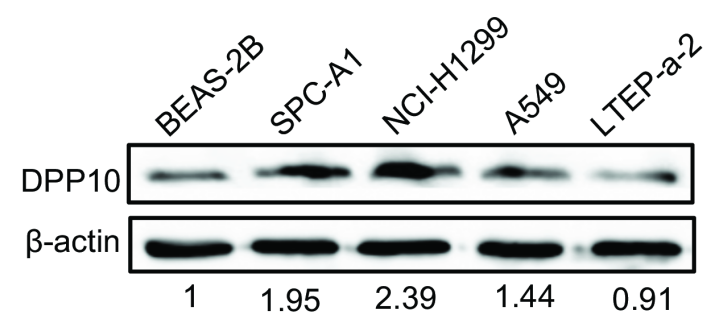

B

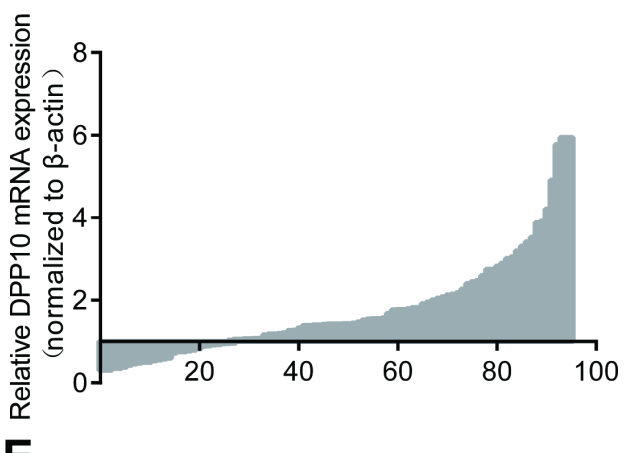

E

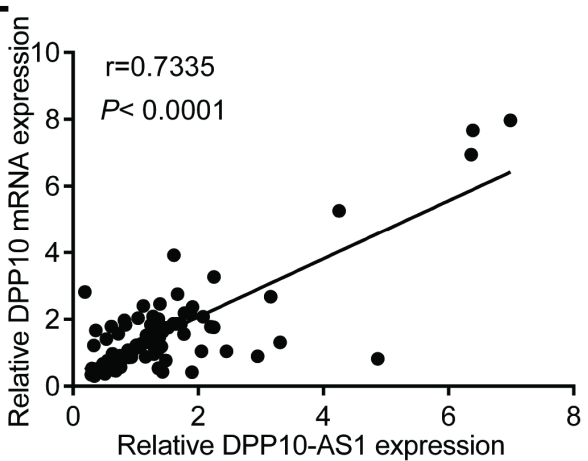

C

$\mathbf{F}$
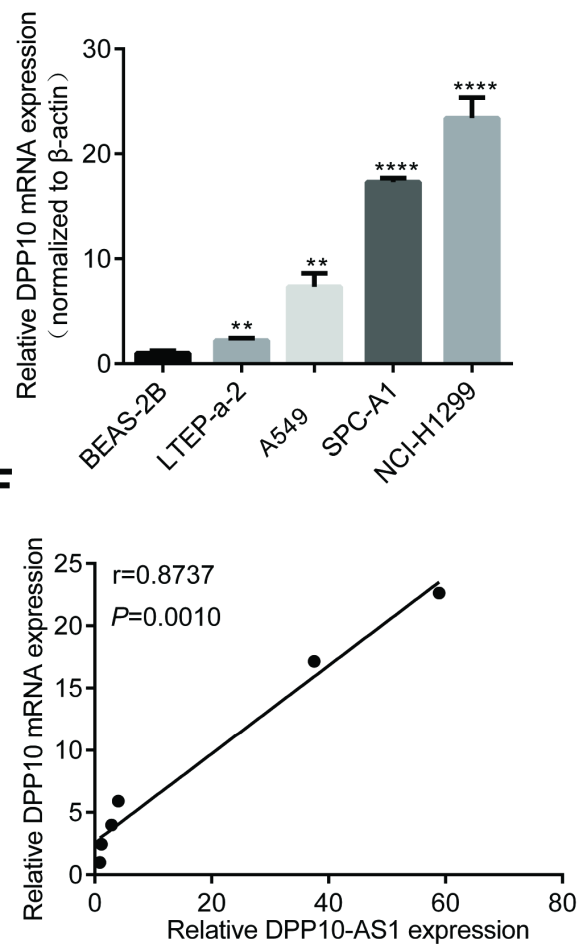

Figure 5

DPP10-AS1 and DPP10 are coordinately upregulated in lung cancer. (A) Difference in expression level of DPP10 mRNA between lung cancer tissues and adjacent cancerous tissues. $\beta$-actin served as the internal control for normalization. The statistical difference was analyzed by Wilcoxon signed-rank test. (B) The ratio between the relative quantification of DPP10 mRNA expression in lung cancer tissues vs. paired adjacent noncancerous lung tissues of each case. qRT-PCR (C) and Western blot (D) analysis of the relative expression of DPP10 mRNA and protein level in lung cell lines. The correlation between DPP10AS1 and DPP10 mRNA in lung cancer tissues $(E)$ and cell lines $(F) .{ }^{*} P<0.05,{ }^{\star} * P<0.01,{ }^{*} * \star * P<0.0001$. 

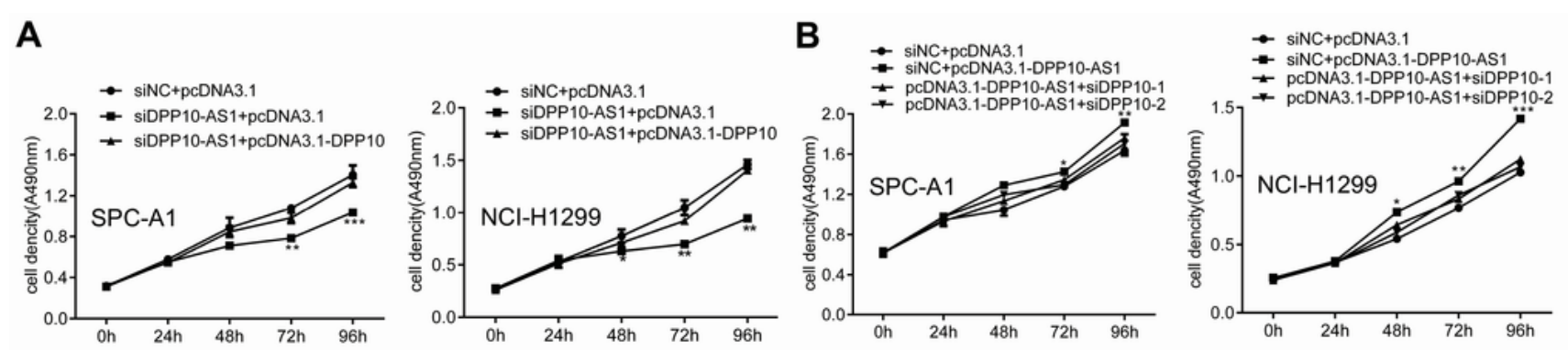

C
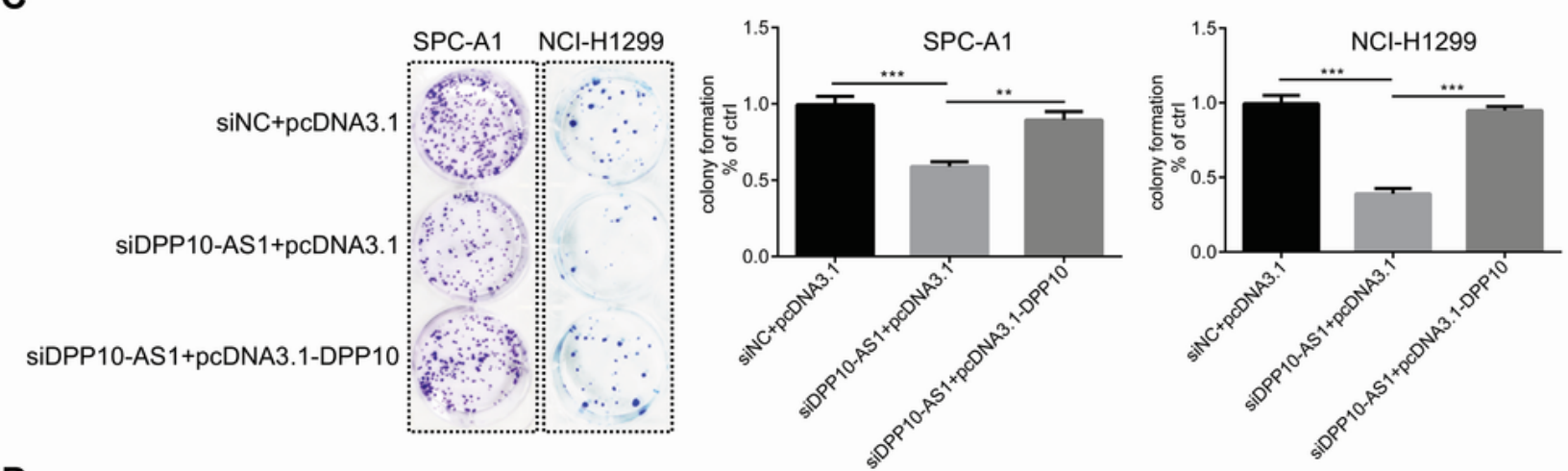

D
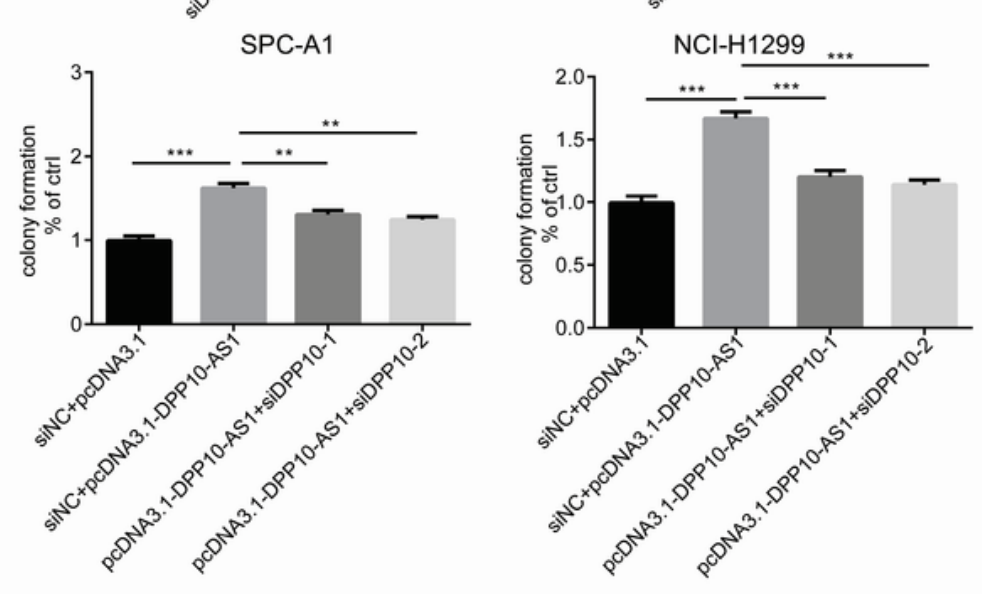

E
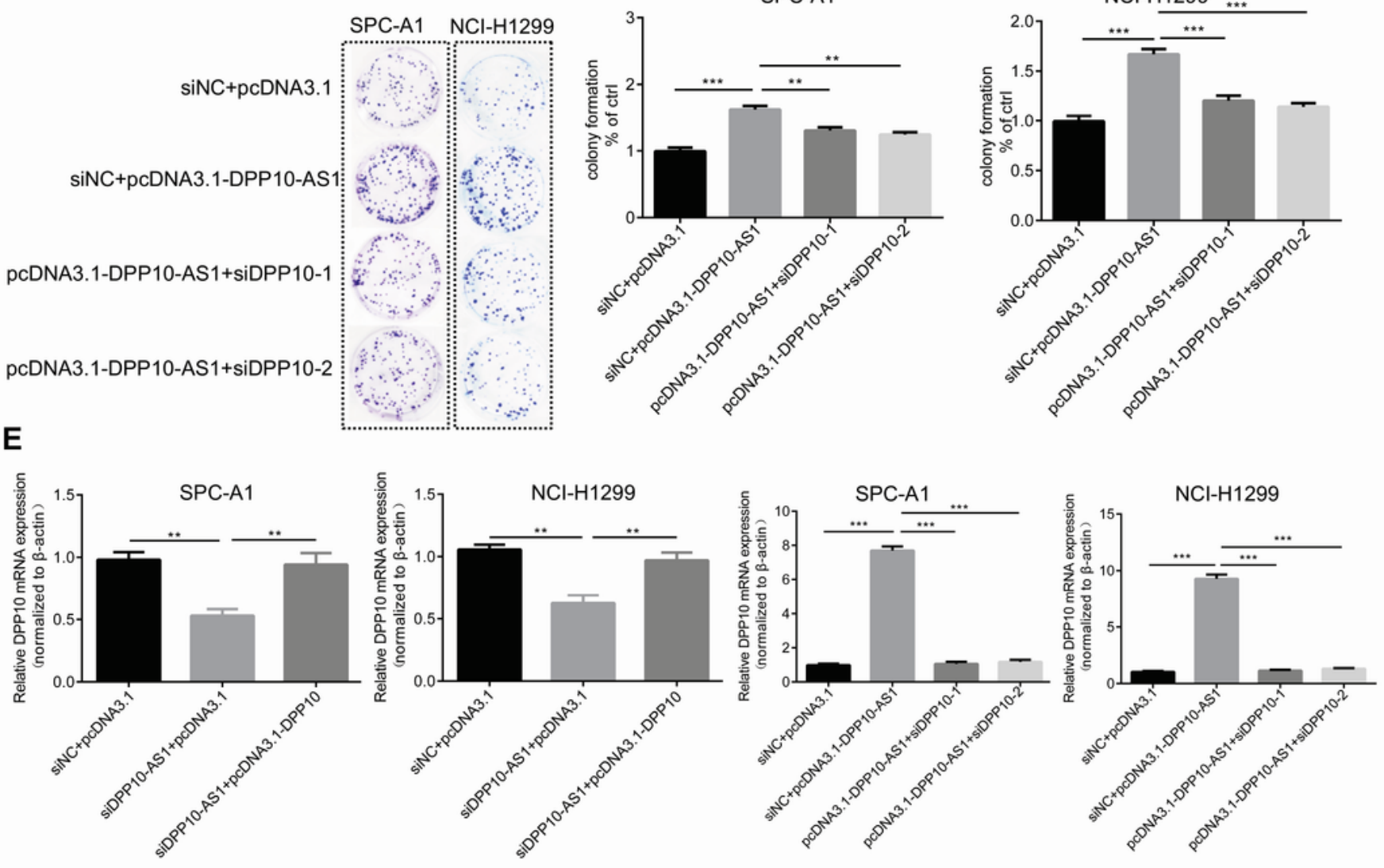

\section{Figure 6}

DPP10-AS1 promotes lung cancer cell growth and proliferation through upregulating DPP10 mRNA expression. (A) Rescue effect of DPP10 overexpression on DPP10-AS1 knockdown-mediated cell growth inhibition in SPC-A1 and NCl-H1299 cells using MTT assay. (B) Rescue effect of DPP10 knockdown on DPP10-AS1 overexpression-mediated cell growth promotion using MTT assay. (C) Colony formation assay was performed to investigate the effect of DPP10-AS1 knockdown and DPP10 overexpression on 
SPC-A1 and NCl-H1299 cell proliferation. (D) The effect of DPP10-AS1 overexpression and DPP10 knockdown on SPC-A1 and NCl-H1299 cell proliferation was detected by colony formation assay. The number of colonies was counted and statistical analysis was shown in the right. (E) Rescue effects of DPP10 overexpression or depletion on DPP10-AS1-mediated DPP10 mRNA expression changes. Data are shown as mean \pm SD based on three independent experiments. ${ }^{*} P<0.05,{ }^{*} P<00.01,{ }^{*} * * P<0.001$.

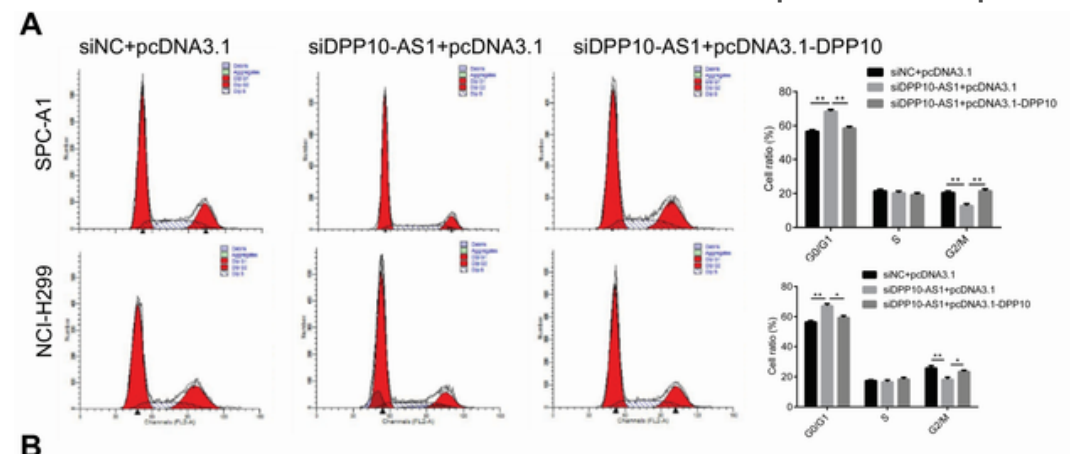

B
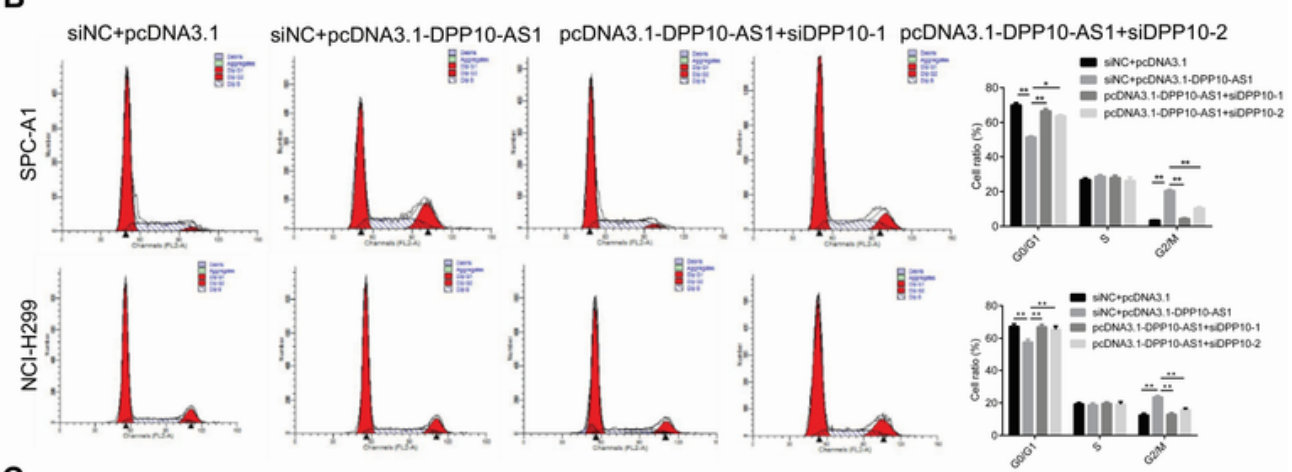

C

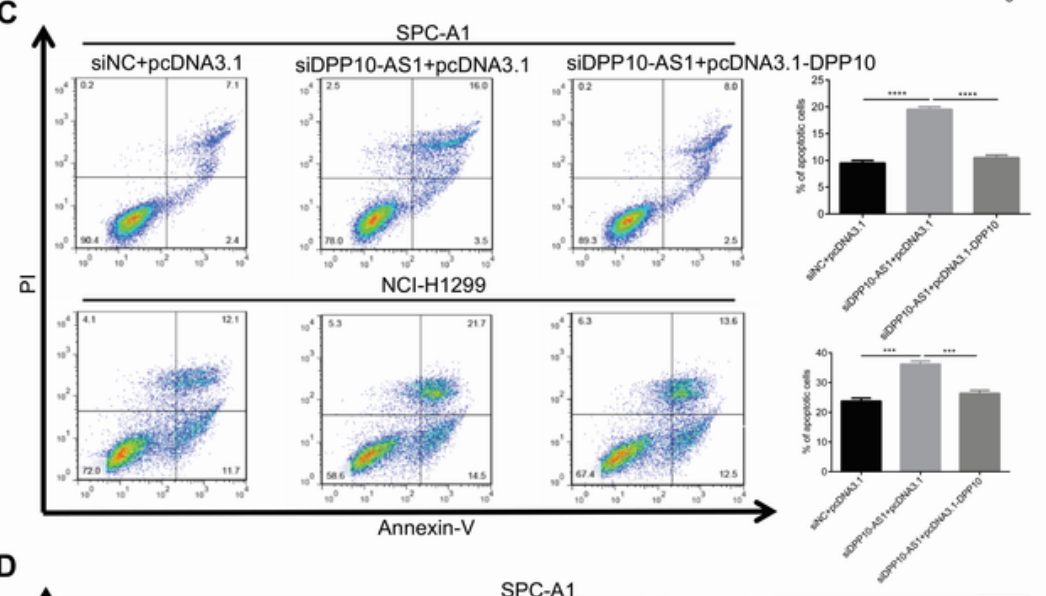

D

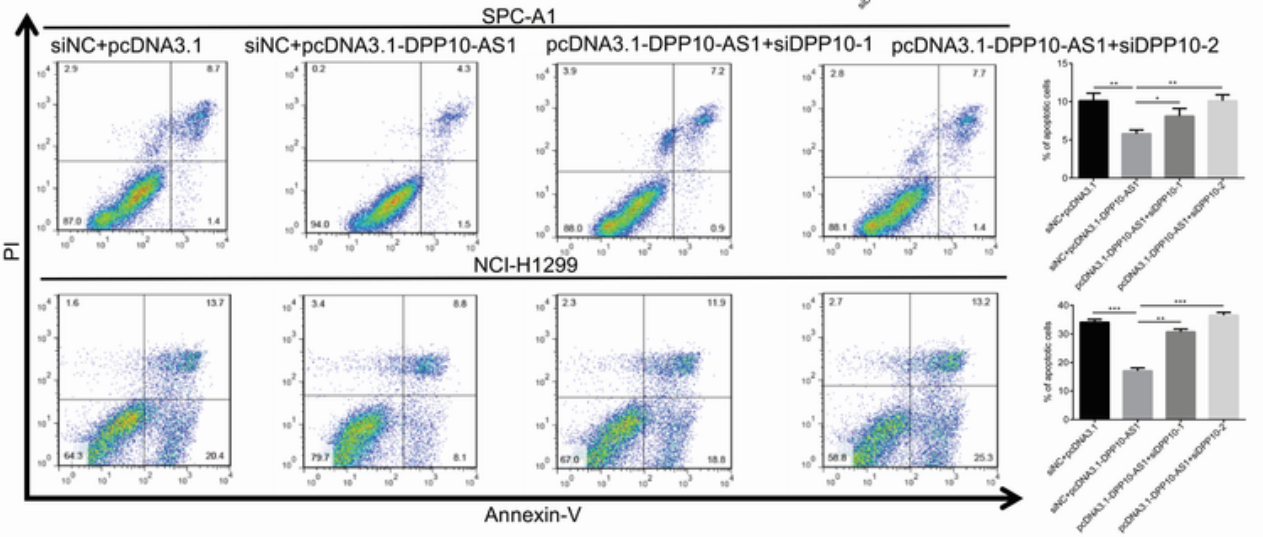

Figure 7 
DPP10-AS1 promotes cell cycle progression and inhibits apoptosis by upregulating DPP10 mRNA. (A) Effects of DPP10-AS1 knockdown and DPP10 overexpression on SPC-A1 and NCI-H1299 cell cycle were assessed by flow cytometry. (B) Effects of DPP10-AS1 overexpression and DPP10 knockdown on SPC-A1 and $\mathrm{NCl}-\mathrm{H} 1299$ cell cycle were assessed by flow cytometry. (C) Effects of DPP10-AS1 knockdown and DPP10 overexpression on SPC-A1 and NCl-H1299 cell apoptosis were assessed by flow cytometry with Annexin V/PI staining. (D) Effects of DPP10-AS1 overexpression and DPP10 knockdown on SPC-A1 and $\mathrm{NCl}-\mathrm{H} 1299$ cell apoptosis were assessed by flow cytometry with Annexin V/PI staining. Data are shown as mean \pm SD based on three independent experiments. ${ }^{*} P<0.05,{ }^{* *} P<0.01,{ }^{\star * *} P<0.001,{ }^{* \star \star *} P<0.0001$. 


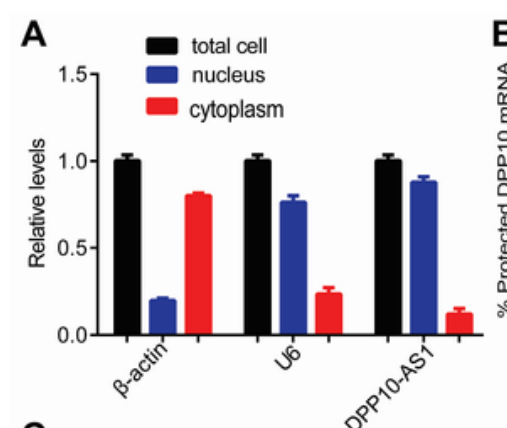

C

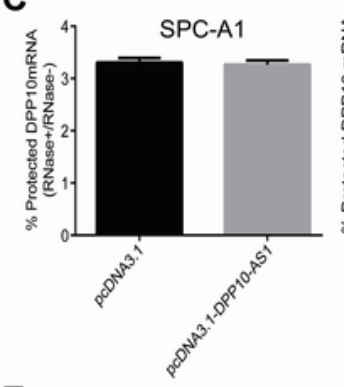

$\mathbf{E}$

G
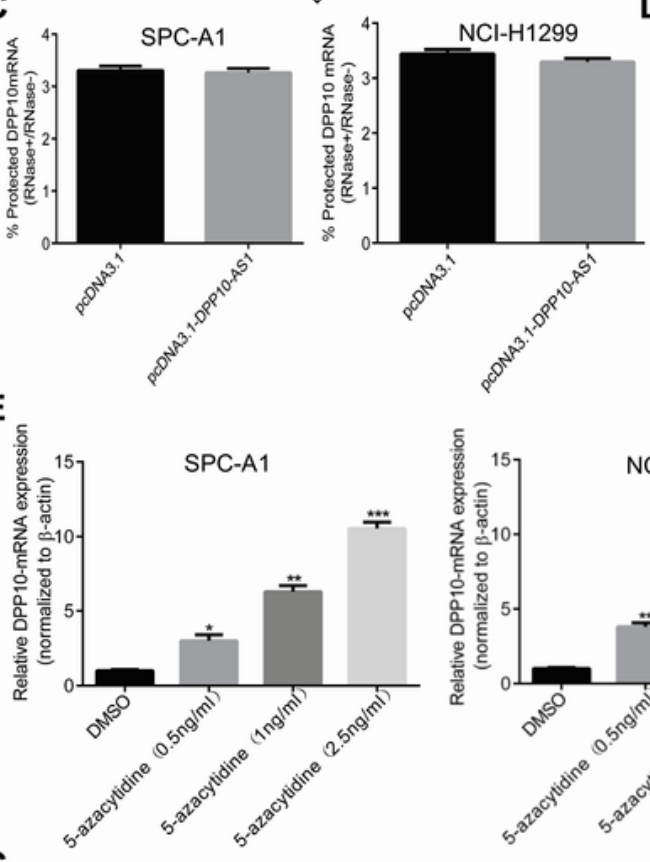

$D^{s}$
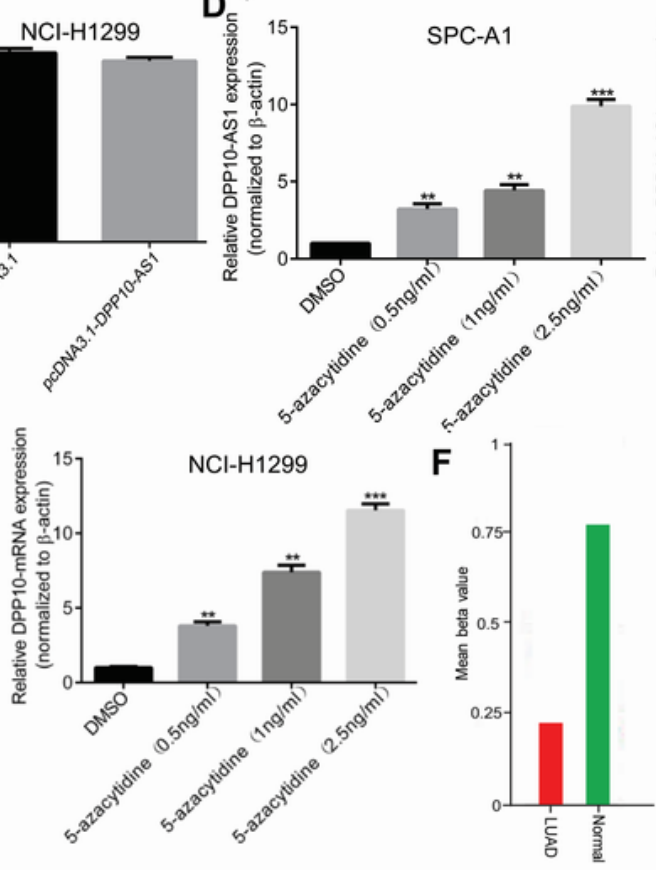
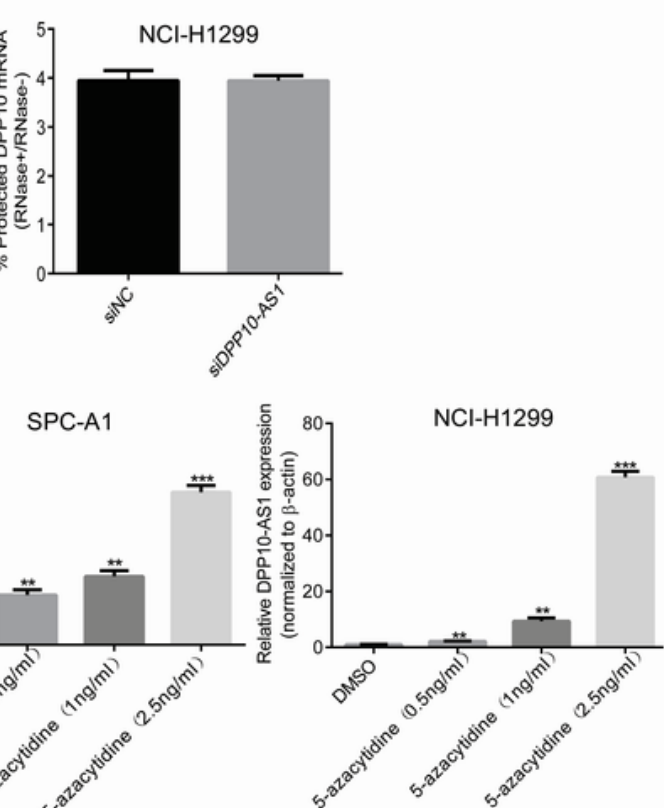

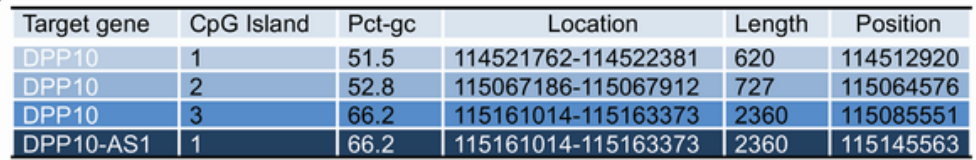

H

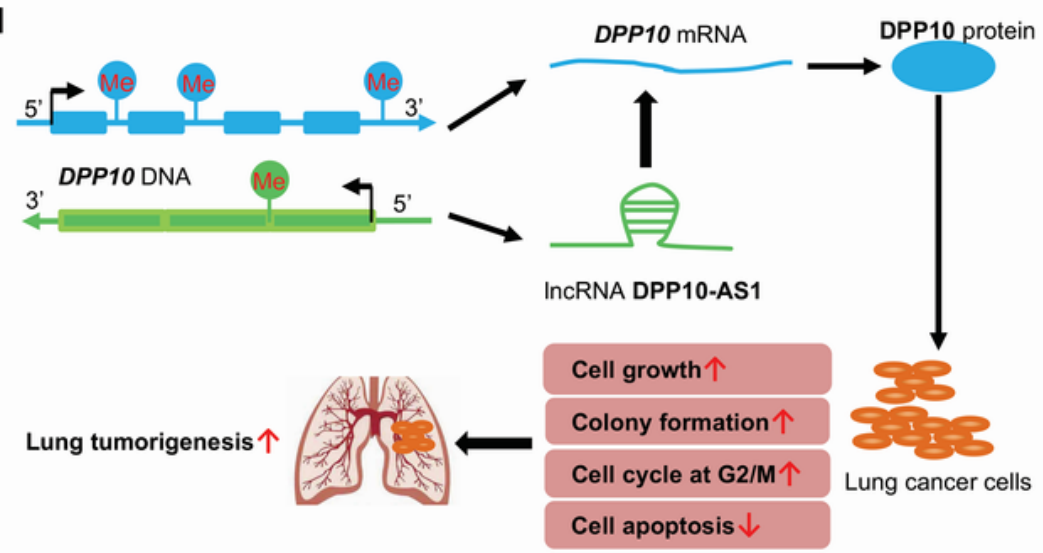

\section{Figure 8}

DPP10-AS1 does not increase DPP10 mRNA stability, but they are regulated by epigenetic methylation. (A) qRT-PCR analysis of DPP10-AS1 in the nucleus and cytoplasm by cytoplasmic and nuclear extract isolation assay. (B) qRT-PCR analysis of DPP10 mRNA levels in SPC-A1 and NCI-H1299 cells cotransfected with siDPP10-AS1 by RNase protection assay. (C) qRT-PCR analysis of DPP10 mRNA levels in SPC-A1 and NCI-H1299 cells cotransfected with pcDNA3.1-DPP10-AS1 by RNase protection assay. (D) 
qRT-PCR analysis of DPP10-AS1 levels in SPC-A1 and NCl-H1299 cells treated with different doses of DNA methyltransferase inhibitor 5-azacytidine. (E) qRT-PCR analysis of DPP10 mRNA levels in SPC-A1 and $\mathrm{NCl}-\mathrm{H} 1299$ cells treated with different doses of DNA methyltransferase inhibitor 5-azacytidine. (F) Hypomethylation of DPP10 in lung adenocarcinoma (LUAD) patients compared with normal controls using the LUAD dataset of the TCGA database. (G) Potential CpG islands for DPP10-AS1 and DPP10 predicted by an epigenetic algorithm. ${ }^{\star} P<0.05 \rrbracket^{\star \star} P<0.01 \rrbracket \star \star \star P<0.001$.

\section{Supplementary Files}

This is a list of supplementary files associated with this preprint. Click to download.

- orginalWBimages.pdf

- NC3RsARRIVEGuidelinesChecklistGong.pdf

- AdditionalFile2.docx

- AdditionalFile1.docx 